\title{
Multiple and spin off initiation of atmospheric convectively coupled Kelvin waves
}

\author{
Dariusz B. Baranowski ${ }^{1,2} \cdot$ Maria K. Flatau $^{3} \cdot$ Piotr J. Flatau $^{4} \cdot$ Jerome M. Schmidt $^{3}$
}

Received: 11 August 2016 / Accepted: 30 November 2016 / Published online: 14 February 2017

(C) The Author(s) 2017. This article is published with open access at Springerlink.com

\begin{abstract}
A novel atmospheric convectively coupled Kelvin wave trajectories database, derived from Tropical Rainfall Measuring Mission precipitation data, is used to investigate initiation of sequential Kelvin wave events. Based on the analysis of beginnings of trajectories from years 1998-2012 it is shown that sequential event initiations can be divided into two distinct categories: multiple initiations and spin off initiations, both of which involve interactions with ocean surface and upper ocean temperature variability. The results of composite analysis of the 83 multiple Kelvin wave initiations show that the local thermodynamic forcing related to the diurnal sea surface temperature variability is responsible for sequential Kelvin wave development. The composite analysis of 91 spin off Kelvin wave initiations shows that the dynamic forcing is a dominant effect and the local thermodynamic forcing is secondary. Detail case studies of both multiple and spin off initiations confirm statistical analysis. A multiple initiation occurs in the presence of the high upper ocean diurnal cycle and a spin off initiation results from both dynamic and local thermodynamic processes. The dynamic forcing is related to increased wind speed and latent heat flux likely associated with an
\end{abstract}

Dariusz B. Baranowski

dabar@igf.fuw.edu.pl; dariusz.b.baranowski@jpl.nasa.gov

1 Institute of Geophysics, Faculty of Physics, University of Warsaw, Warsaw, Poland

2 Joint Institute for Regional Earth System Science and Engineering, University of California Los Angeles, Los Angeles, CA, USA

3 Naval Research Laboratory, Marine Meteorology Division, Monterey, CA, USA

4 Scripps Institution of Oceanography, University of California San Diego, La Jolla, CA, USA off equatorial circulation. In addition a theoretical study of the sequential Kelvin waves is performed using a shallow water model. Finally, conceptual models of these two types of initiations are proposed.

Keywords Convectively coupled equatorial waves . Tropical dynamics $\cdot$ Intraseasoanal variability $\cdot$ Air-sea interactions · Diurnal cycle of the SST

\section{Introduction}

Convectively coupled Kelvin waves (CCKWs) are atmospheric weather systems that propagate eastward along the equatorial wave guide with phase speeds between 11 and $14 \mathrm{~ms}^{-1}$ (Roundy 2008). Near the equator CCKWs are the leading modes of eastward moving convection on time scales from several days to 3 weeks (Kiladis et al. 2009). CCKWs, together with other equatorial eastward and westward propagating perturbations, form the "building blocks" of the multi-scale structure in the active phase of the Madden-Julian Oscillations (MJO) (Majda and Khouider 2004; Mapes et al. 2006). The MJO itself is a leading mode of intraseasonal variability in the tropical atmosphere (Lau and Waliser 2011; Madden and Julian 1972; Zhang 2005) with numerous global implications for various components of the weather systems (Zhang 2005; Zhang et al. 2013).

Despite progress in numerical modeling of the tropical convection and its variability, proper representation of initiation, evolution and decay of the MJO and its components remains challenging (Kim et al. 2009; Lin et al. 2006). It has been shown (Guo et al. 2015) that ability of a General Circulation Model (GCM) to represent MJO variability depends on the model's representation of the CCKWs. Recently, Jiang et al. (2015) showed that most of 
state-of-the-art GCMs fail to realistically represent eastward propagating mode of intraseasonal variability, partially due to damped CCKWs activity to the east of convection center. Another model intercomparison study showed that the majority (75\%) of the GCMs surveyed do not accurately represent CCKWs (Straub et al. 2010).

Although CCKWs are important components of the tropical variability, mechanisms of their initiation are poorly understood. Global climatologies (Kiladis et al. 2009; Roundy and Frank 2004) show three peaks of CCKW activity: over South America, Africa and broad peak over the Indian Ocean and Maritime Continent. Various proposed mechanisms responsible for CCKW initiation include extratropical forcing from Rossby wave activity in the Pacific basin (Straub and Kiladis 2003), cold surges propagating equatorward along eastern slope of Andes in South America (Liebmann et al. 2009), indirect effects of midtropospheric wave forcing within the stormtrack belt in the Southern Hemisphere (Yang et al. 2007). Another group consists of circumnavigating Kelvin waves, which may be purely dynamical (dry), moist or transition between those two kinds (Gottschalck et al. 2013; Knutson and Weickmann 1987). Haertel et al. (2015) showed that transition of such a wave from dry to convectively coupled can force a MJO event. Therefore, a CCKW emergence may be preceded by dynamic precursors in low and high level winds.

A recent study, based on analysis of the CCKW trajectories (Baranowski et al. 2016) showed that in the Indian Ocean $\left(50-100{ }^{\circ} \mathrm{E}\right)$ number of CCKW initiations is high $\left(11 \pm 3\right.$ initiations in each $1^{\circ}$ longitude bin) and number of ending trajectories is low ( $3 \pm 2$ terminations). That suggests that local environmental conditions are favorable for CCKW initiation over broad area in the Indian Ocean basin. This region is characterized by a high frequency of occurrence of strong upper ocean diurnal warm layers (Matthews et al. 2014) which are responsible for additional energy flux from the ocean surface to the atmosphere delivered in a form of a daily pulses.

In the past, the problem of a transient response of dry Kelvin waves to the sharp forcing was investigated (Silva Dias et al. 1983). It was shown that a temporal characteristic of the forcing is important for the Kelvin wave response: the amount of Kelvin wave energy generated is greater when the forcing is rapid.

A recent study by Ruppert and Johnson (2015) shows that diurnal SST variability is reflected in the diurnal cycle of the heating profiles in the atmosphere. Those authors show that the low to midlevel moistening during the suppressed phase of the MJO is accomplished by a population of shallow cumulus and congestus clouds that exhibits a pronounced diurnal cycle in response to oceanic diurnal warm layers. The analysis of the suppressed phase revealed that the moistening characteristic of this period is accomplished by the diurnal cycle of cumulus clouds. The diurnal cycle in atmospheric convection is driven by the cycle in sea surface temperature and air-sea fluxes linked to shallow oceanic diurnal warm layer development. An afternoon peak in convective cloud depth, cloud areal coverage, and cumulus moistening are associated with this coupled diurnal cycle. In effect, the overall moistening is more vigorous than would occur without it. Subsequent modeling work (Ruppert 2016; Ruppert and Johnson 2016) emphasizes importance of the direct impact of the shortwave radiation on convection development and suggests that diurnal oceanic warm layers and the resulting diurnal cycle of SST is not the complete picture. Model studies suggest that in the absence of other forcing, the diurnal oscillation of precipitation responds to the diurnal variability of SST (Chen et al. 2015; McLay et al. 2012). These results provide motivation to use the diurnally varying heat source in the idealized numerical simulations to study initiation of equatorial waves (which we discuss in the Appendix). Another example of a feedback between upper ocean and atmospheric convection is a 2-day wave phenomena which was shown to develop in response to the development and evolution of warm layers (Chen and Houze 1997).

In this paper we are interested in assessing an impact of short term variability of surface fluxes and SST on the initiation of coupled waves in tropical atmosphere, in particular initiations of CCKWs over the Indian Ocean basin. We investigate initiations of precipitating, convectively coupled events and refer to any occurrence of a CCKW as its initiation, regardless of its precursors. In that sense, the coupling or recoupling to the convection within one longer or even circumnavigating event is still considered a CCKW initiation.

Our main observational datasets are TRMM 3B42 v7 (Huffman et al. 2007) precipitation data and surface fluxes from OAFlux product (Yu et al. 2008). Such datasets were used in numerous studies of tropical convection including MJO dynamics (Masunaga et al. 2006), monsoon (Houze et al. 2007) and hurricanes (Hence and Houze 2011).

We will also use a shallow water model to investigate influence of diurnal variability of the heat source on the zonal structure of tropical waves. A similar nonlinear shallow-water model on the sphere was used to study barotropic aspects of the formation of twin tropical disturbances by MJO convection (Ferreira et al. 1996).

The paper is organized as follows. Section 2 presents case studies of two types of sequential CCKWs initiations-multiple (Sect. 2.1) and spin-off (Sect. 2.2); Sect. 3 gives analysis of composite environmental conditions for both groups of sequential CCKW initiations; Sect. 4 contains discussion of proposed initiation mechanisms and a summary. Additionally, we include an Appendix, which 
comprehensively describes set up and results of a shallow water modeling. Results of the simulations are important for our observational analysis of multiple initiations of CCKWs; observational and modeling results are explicitly linked in the text. We put full description these results in Appendix to keep our narrative flowing and on point, while giving a Reader the opportunity to understand implications of the non-linear diurnal forcing on structure of Kelvin waves.

\section{Case study of initialization of sequential CCKW}

In this paper we will be using a novel database of CCKW trajectories that allows lagrangian analysis of the propagating events. The database has been introduced and is described in more detail in Baranowski et al. (2016), here we provide just a short summary. The CCKW trajectories are defined by performing a wavenumber-frequency filtering on the TRMM 3B42 precipitation data (Huffman et al. 2007) averaged between $2.5 \mathrm{~S}$ and $2.5 \mathrm{~N}$, following methodology of Wheeler and Kiladis (1999). For example, we filter for in the band bounded by frequencies $1 / 30 \mathrm{cpd}$ and 4/10cpd, zonal wavenumbers 1 and 14 and shallow water model equivalent depths of 8 and $90 \mathrm{~m}$. Next, the local maxima of the filtered precipitation are calculated. The two nearby maxima are considered part of the same trajectory when they occur within $6 \mathrm{~h}$ of each other. Such derived trajectory is quality controlled against unfiltered precipitation data to correct potential discrepancies in the location of the beginning and end of each trajectory (Baranowski et al. 2016).

Atmospheric and oceanic conditions at the ocean surface are assessed using daily estimates of wind speed, latent heat flux and SST on $1 \times 1$ degree grid provided by the OAFlux (Yu et al. 2008). All data are averaged in the equatorial belt $(2.5 \mathrm{~S}-2.5 \mathrm{~N})$ in order to create surface fluxes consistent with the precipitation data and CCKW trajectories. An estimate of magnitude of the upper ocean temperature diurnal cycle is based on the TropFlux dataset (Praveen Kumar et al. 2013) following methodology described by Matthews et al. (2014) and Baranowski et al. (2016). It uses daily mean values of shortwave radiation flux and wind speed at the ocean surface to estimate the daily mean diurnal SST anomaly.

The CCKW database contains 1840 trajectories that occurred between January 1998 and December 2012. An analysis of the areas of origin and end of individual CCKW trajectories reveals that Indian Ocean basin has the highest number of trajectory initiation and that the Maritime Continent is one of the major dissipation areas (see Fig. 1). Out of all 1840 trajectories worldwide, 758 occurred in the

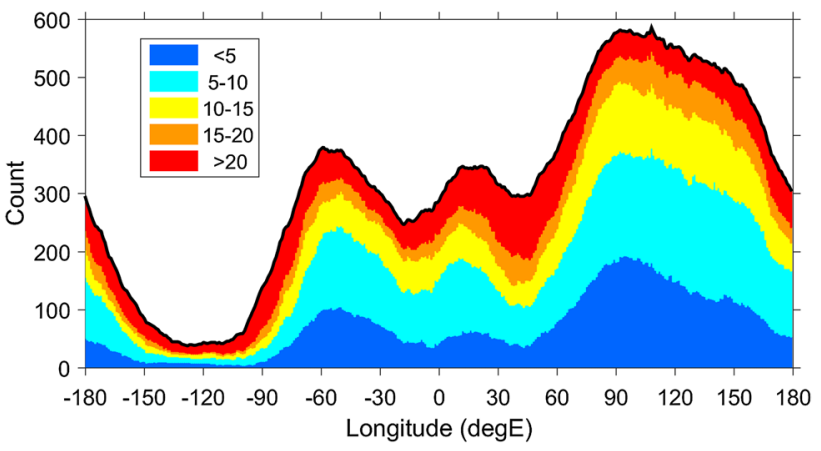

Fig. 1 Number of active Kelvin waves for each longitude stratified by the time between two Kelvin waves: blue color indicates waves reoccurring within 5 days of each other; light blue indicates waves reoccurring between 5 and 10 days after each other; yellow indicates waves reoccurring between 10 and 15 days after each other; orange indicates waves reoccurring between 15 and 20 days after each other; red indicates waves reoccurring more than 20 days after preceding one. The $x$-axis is longitude in (degE), $y$-axis is Kelvin wave count

Indian Ocean basin defined as the area between east coast of Africa (40E) and west coast of Sumatra (100E).

In Fig. 1 the longitudinal distribution of trajectories as a function of a frequency of reoccurrence is shown. Reoccurrence indicates the time, which passed from a preceding CCKW passage. It can be seen that with an increase in overall count of active CCKWs through the Indian Ocean, a fraction of the waves with the shortest reoccurrence time (blue and light blue) increases as well. There is no reason to expect that areas of high CCKW activity should have different reoccurrence fractions. However, the fraction of CCKWs with reoccurrence time shorter than 5 days is the highest in the eastern Indian Ocean. In fact, CCKWs reoccurring within $<10$ days (blue and light blue color) account in that area for more than $60 \%$ of all active trajectories in that region. It can be seen that the fraction of CCKWs reoccurring within 10-20 days is globally the same. There is a small number of waves reoccurring with even longer periods. Thus, the majority of the cross-basin differences in CCKW activity are associated with events, which come quickly after each other, and this is especially true in the Indian Ocean basin. The fact that there are so many CCKWs in that basin, and that they come relatively fast after each other, indicates that the local environment favors these waves and that it may be modified by them through the air-sea interaction.

In what follows, we limit analysis to the Indian Ocean and two categories will be identified: multiple initiation and spin-off initiation, both of which depend on interactions between waves and the surrounding environment.

Several cases of CCKW initiation are selected from the database just described and used to diagnose atmospheric and oceanic conditions at the ocean surface. Here, 

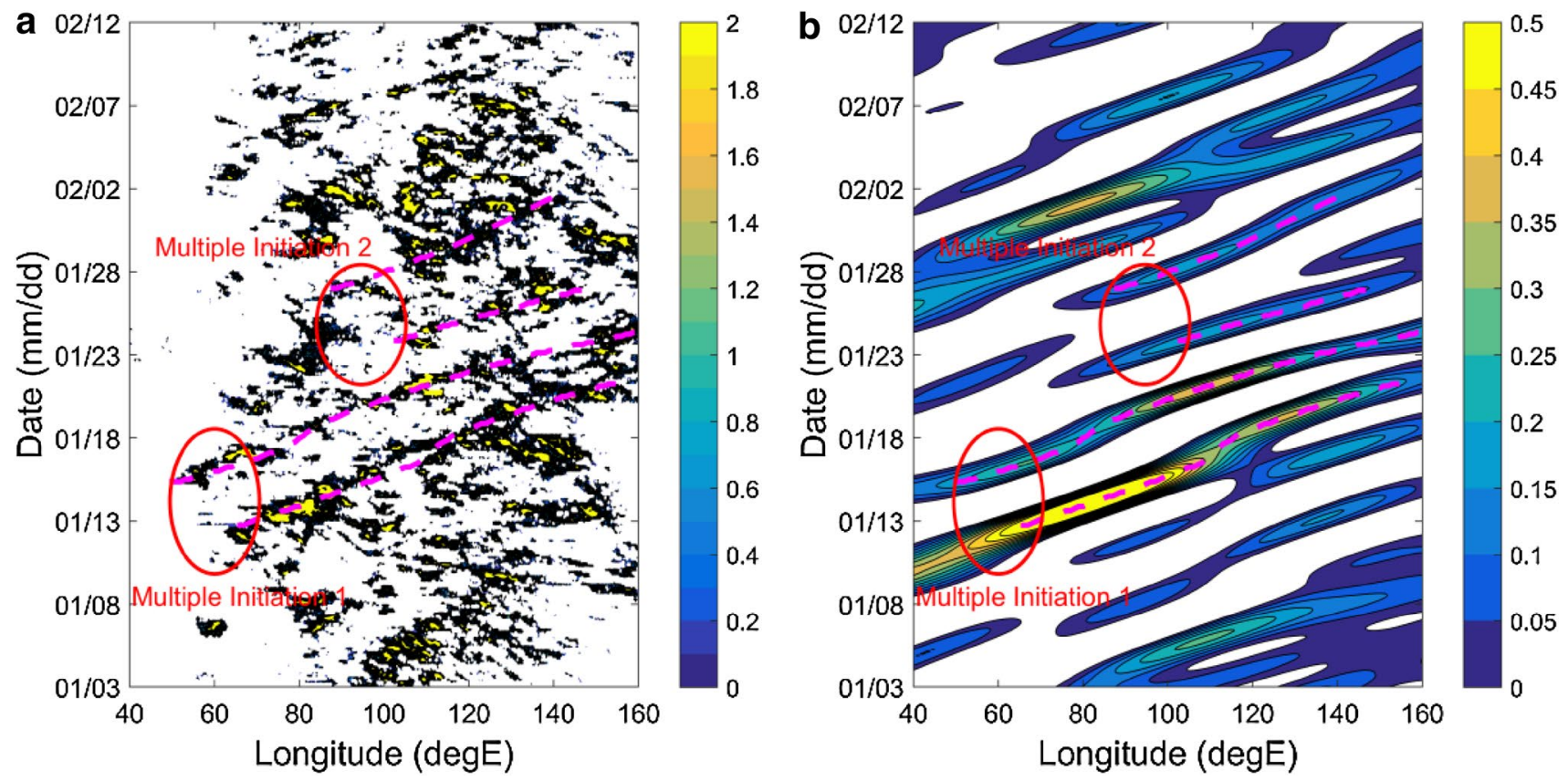

Fig. 2 TRMM precipitation in $\left(\mathrm{mm} \mathrm{h}^{-1}\right)$ during the period between January 3 and February 12, 2000. The $x$-axis is longitude in (degE); the $y$-axis is time in ( $\mathrm{mm} / \mathrm{dd})$. Magenta lines indicate Kelvin wave trajectories

variability of the surface wind speed, latent heat flux, magnitude of the upper ocean temperature diurnal cycle and SST in the vicinity of the CCKW initiation will be of our primary interest.

\subsection{Multiple initiation}

We define multiple initiations as CCKWs occurring in the same general area within few days from each other. In this study we define time and space thresholds to be 5 days and $10^{\circ}$.

An example of multiple initiations is presented in Figs. 2, 3, 4, 5 and 6. All CCKW trajectories are marked with magenta lines, based on trajectory database. The area of interest is indicated by red ellipsis. In January 2000 two CCKWs were initiated over the western Indian Ocean (around 60E). It can be seen in Fig. 2 that the precipitation associated with these two disturbances began over that area. The precipitation associated with the first CCKW initiated on January 12 at $63 \mathrm{E}$ and the precipitation associated with the second CCKW began on January 15 at 54E. Figure 4 shows that the area between $60 \mathrm{E}$ and $80 \mathrm{E}$ during the period between January 5, 2000 and February 5, 2000 was characterized by relatively weak wind speeds in the first half of that period and slightly higher wind speeds in the second half of that period. Variability in wind speeds is reflected in the variability of the latent heat flux at the ocean surface which was small in the first half of January and slightly higher in the latter one (Fig. 5). The SST was in the $28.5-29.0{ }^{\circ} \mathrm{C}$ range, which is high, but smaller than the SST over the eastern Indian Ocean during the same period (Fig. 6). This time period is also characterized by high magnitudes of diurnal SST variability with large number of days for which

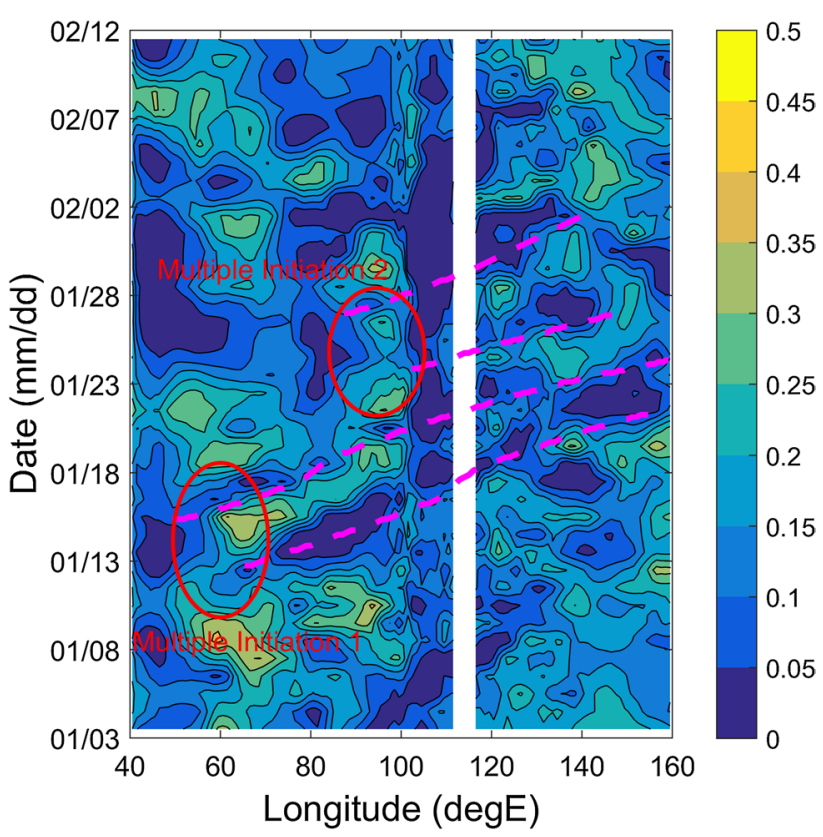

Fig. 3 Same as Fig. 2 but for the derived magnitude of the upper ocean temperature diurnal cycle in $\left({ }^{\circ} \mathrm{C}\right)$ 


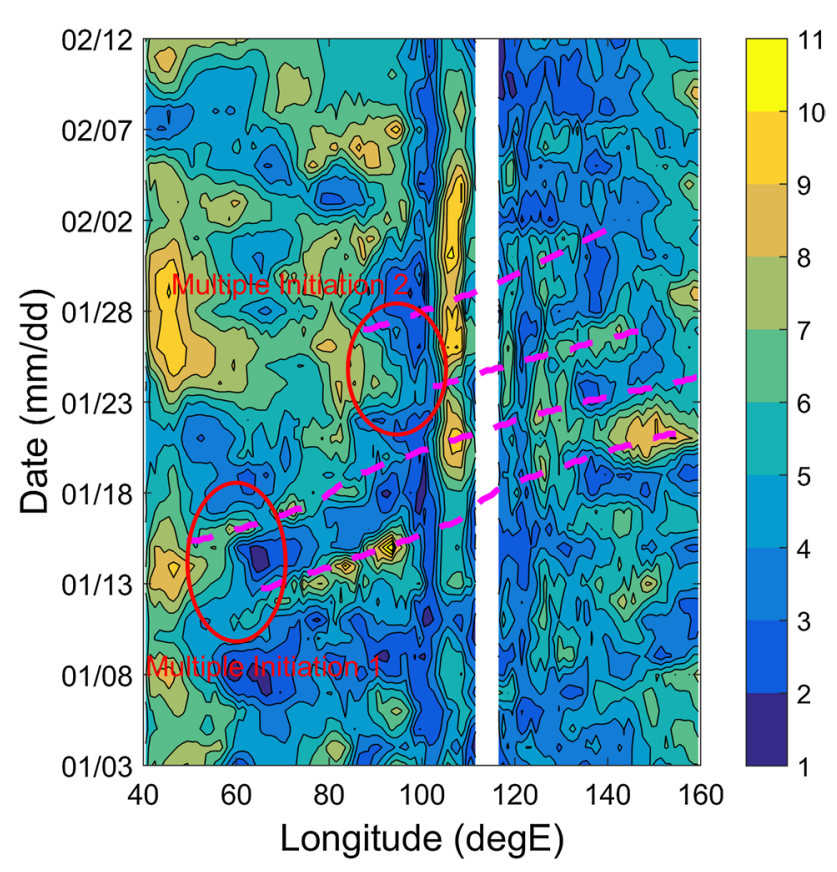

Fig. 4 Same as Fig. 2 but for the ocean surface wind speed in $\left(\mathrm{ms}^{-1}\right)$. Figure 4 same as Fig. 2 but for the ocean surface wind speed in $\left(\mathrm{ms}^{-1}\right)$

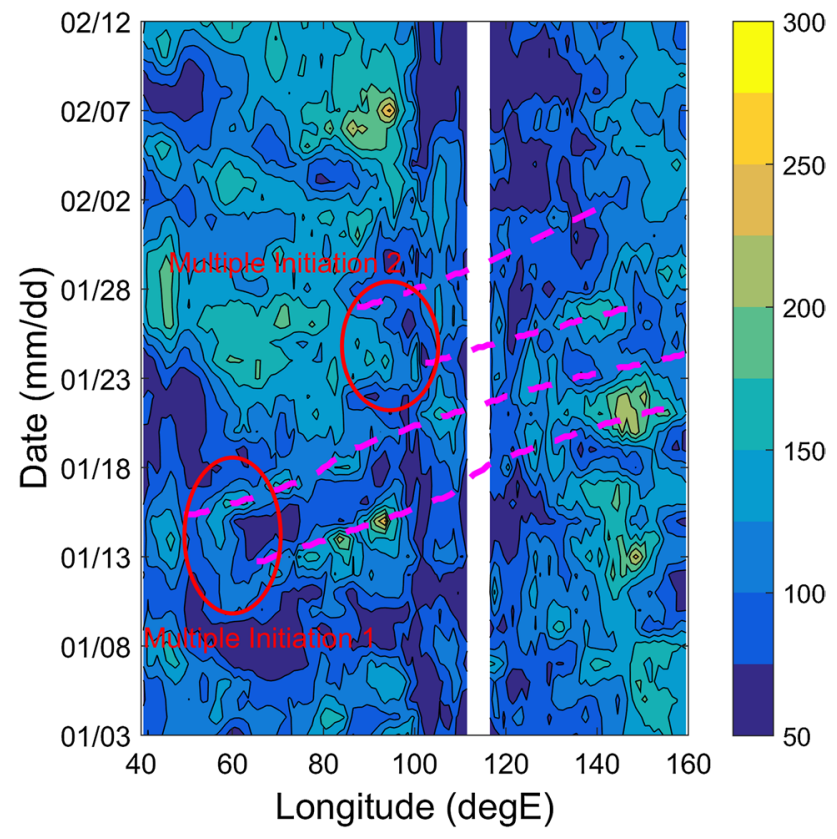

Fig. 5 Same as Fig. 2 but for the ocean surface latent heat flux in $\left(\mathrm{Wm}^{-2}\right)$

daily mean SST anomaly at the ocean surface exceeded $0.35^{\circ} \mathrm{C}$; that is relatively large and corresponds to maximum diurnal anomaly of approximately $1{ }^{\circ} \mathrm{C}$ (Fig. 3). The location of the initialization of the precipitation

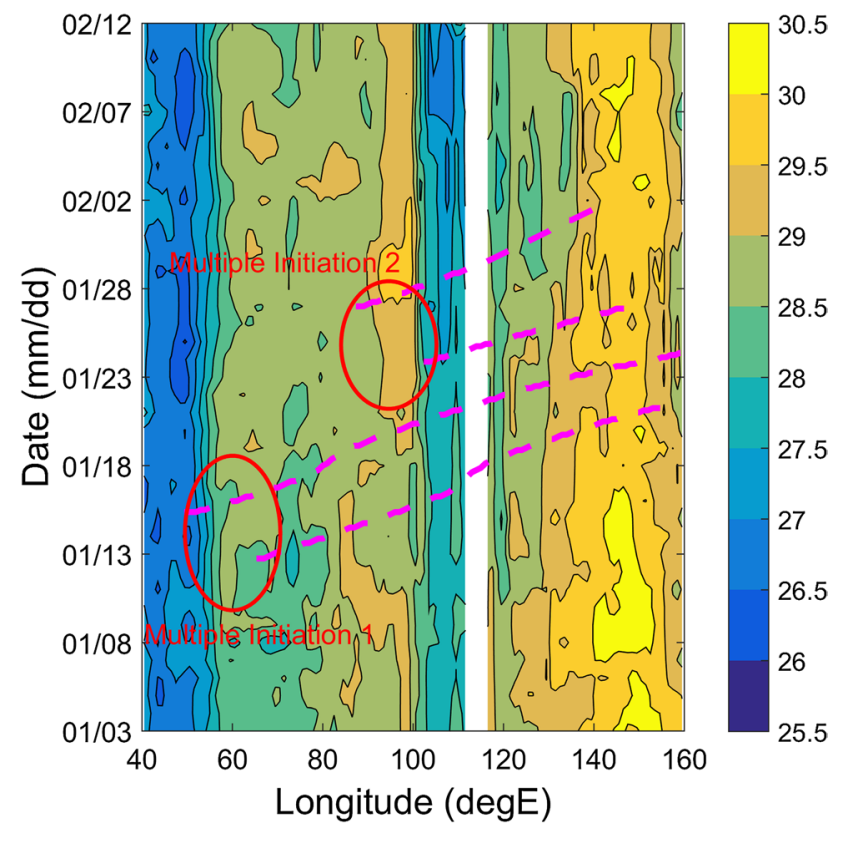

Fig. 6 Same as Fig. 2 but for the SST in $\left({ }^{\circ} \mathrm{C}\right)$

associated with these CCKWs agrees well with time and location of the area of strong upper ocean temperature diurnal cycle and weak latent heat flux. This suggests that diurnally increased surface fluxes, due to development of a diurnal warm layer at the ocean surface, might have contributed to the subsequent development of an atmospheric convection and this, in turn, contributed to formation of two individual CCKWs.

Analysis of the trajectories shows two more CCKWs (marked with the red ellipsis) initiated within few days around January 23 at $90 \mathrm{E}$. At that time and location the wind speed is higher which causes higher values of latent heat flux at the ocean surface. The diurnal SST variability in the area identified as CCKWs initiation is increased but is not as strong as in the previous case. Increased values of the magnitude of the diurnal SST variability are observed as well, which leads to convective precipitation onset; this is consistent with the previous case study.

In summary, we considered two cases of multiple initiations. One pair of multiple CCKWs was initiated in the area of increased SST variability and relatively weak wind speed and latent heat flux. The other pair of multiple CCKWs was initiated in the area where the SST variability, wind speed and latent heat flux were larger. These case studies suggest that both the upper ocean temperature diurnal variability and ocean surface flux variability are important factors for formation of convection and precipitation, especially when they are organized in multiple CCKWs. Such link between atmospheric convection and upper ocean diurnal variability was noted previously (Chen et al. 2015; 

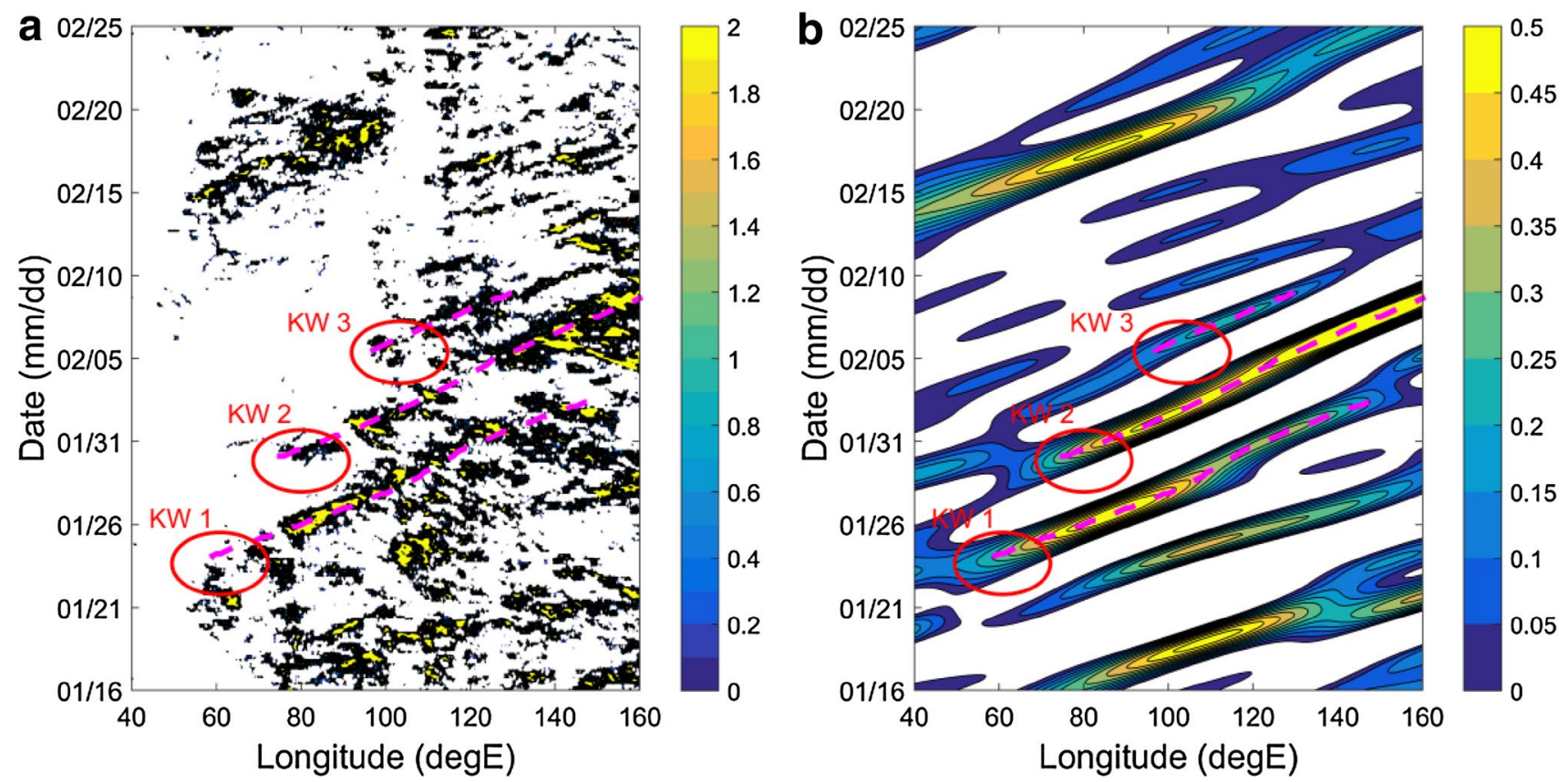

Fig. 7 TRMM precipitation in $\left(\mathrm{mm} \mathrm{h}^{-1}\right)$ during the period between January 16 and February 25, 2004. The $x$-axis is longitude in (degE); the $y$-axis is time in ( $\mathrm{mm} / \mathrm{dd})$. Magenta lines indicate Kelvin wave trajectories

Ruppert and Johnson 2015) and it will be further elaborated using composites of multiple $\mathrm{CCKW}$ initiation cases and a modeling study.

\subsection{Thermodynamic spin off initiation}

A thermodynamic spin off initialization takes place when sequential CCKWs are forced in temporal proximity to a preceding and mature CCKW. In contrast to the previously described multiple initiation category, a spatial proximity constrain is relaxed so that the two disturbances do not initiate in the same area, but the latter wave has to begin in location where the first one was active and therefore might have preconditioned the environment or even induced development of the sequential disturbance. Hence, the latter CCKW is a spin off from the preceding one. On the other hand, a temporal proximity threshold has been set to 5 days as was previously. It means that in a spin off initiation, a sequential wave begins more than $10^{\circ}$ east from an area where a preceding event began. We decided to keep the temporal constrain set to 5 days because beyond that period there is no reason to expect that the diurnal cycle is influenced by the preceding wave. In Baranowski et al. (2016) we showed that the magnitude of the diurnal cycle is strongest 2 days after a passage of a developed CCKW. Additionally, a predominant period of CCKW occurrence is 5 days, so clear sky, non-convective conditions preceding CCKW development, should persist for up to 5 days.
An example of spin off waves is presented in Figs. 7, 8, 9, 10 and 11. These CCKWs were active in Indian Ocean basin in the second half of January and during the February of 2004. During the period between January 23 and February 4 three CCKWs initiated between longitudes $51 \mathrm{E}$ and $98 \mathrm{E}$. Each of these three consecutive CCKWs

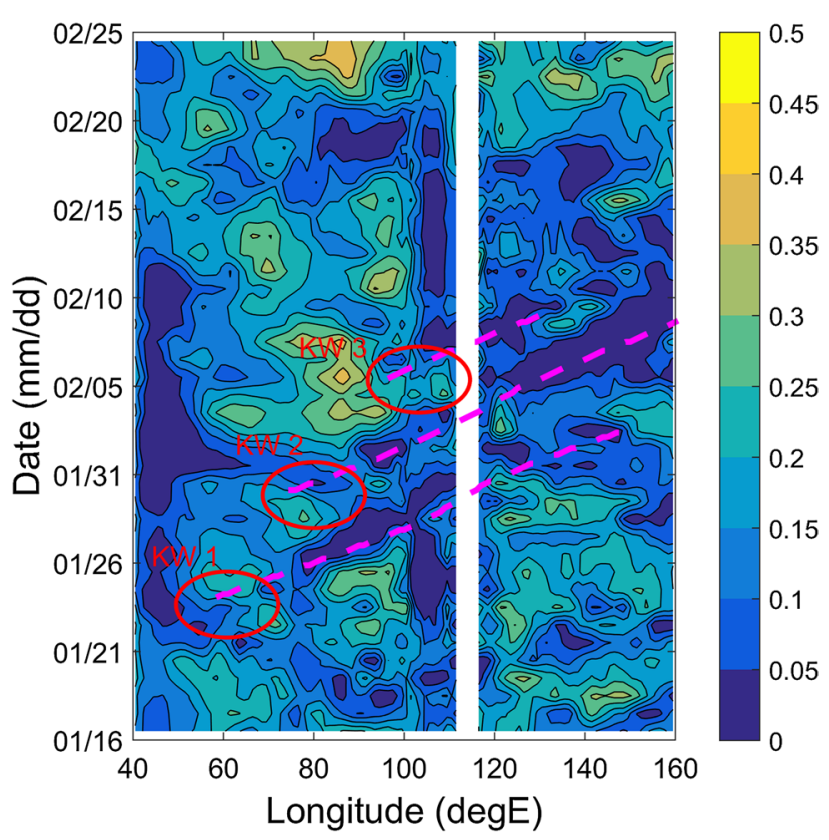

Fig. 8 Same as Fig. 7 but for the derived magnitude of the upper ocean temperature diurnal cycle in $\left({ }^{\circ} \mathrm{C}\right)$ 


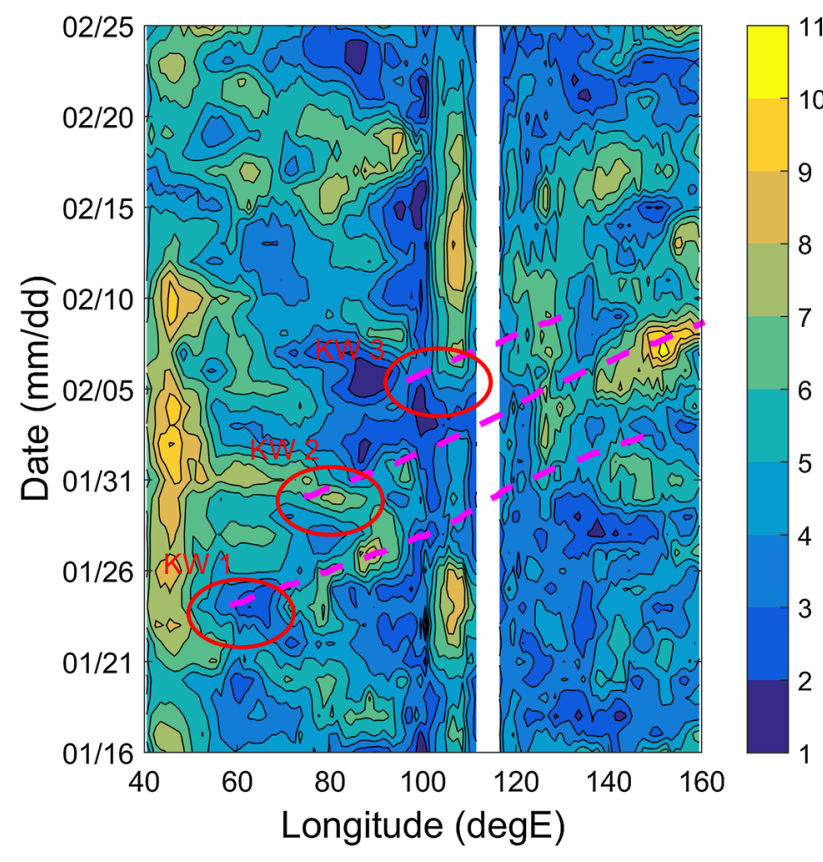

Fig. 9 Same as Fig. 7 but for the ocean surface wind speed in $\left(\mathrm{ms}^{-1}\right)$

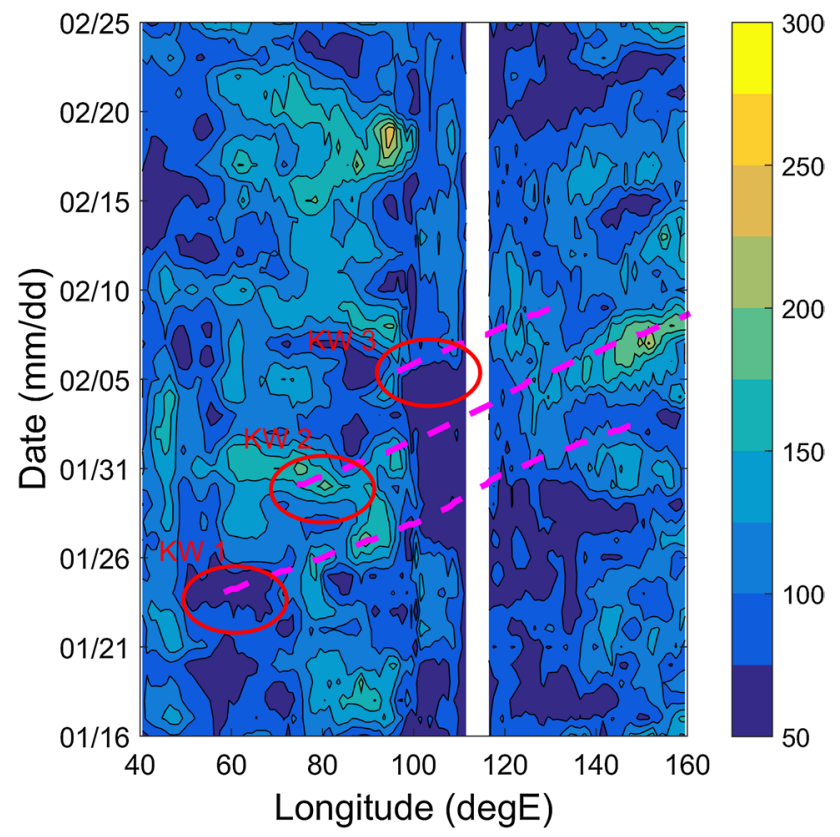

Fig. 10 Same as Fig. 7 but for the ocean surface latent heat flux in $\left(\mathrm{Wm}^{-2}\right)$

originated further east. The first CCKW appeared on January 23 at $51 \mathrm{E}$ and passed over $70 \mathrm{E}$ on January 25 . Approximately 4.5 days later the second CCKW initiated at 70E. This disturbance passed over the $98 \mathrm{E}$ on February 1 . About 4 days later the third CCKW originated at the same location. Distance between the first and the

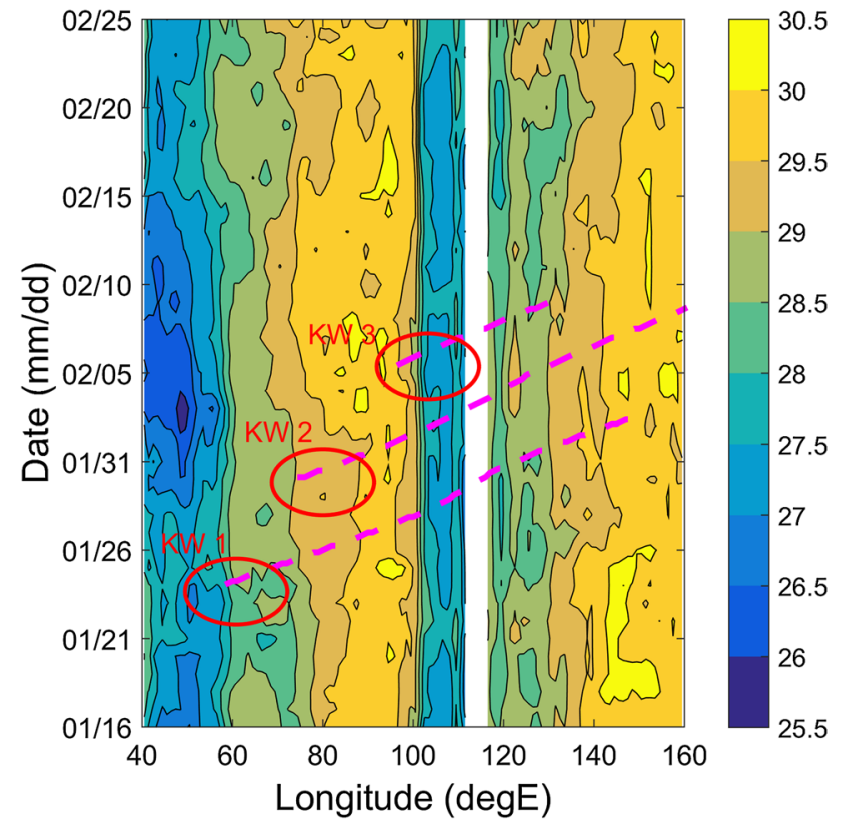

Fig. 11 Same as Fig. 7 but for the SST in $\left({ }^{\circ} \mathrm{C}\right)$

second as well as between the second and the third of these consecutive CCKWs was bigger than 10 degrees and time between them was $<5$ days which makes the later two of them candidates for a thermodynamic spin off initialization.

The environmental conditions along the three consecutive CCKW trajectories resemble features linked to typical interactions between CCKW and the surrounding environment as described in the previous chapter. These features at the ocean surface include decrease in the diurnal SST variability, increase in the wind speed and subsequent increase in values of the latent heat flux along the CCKW trajectory. A typical scenario includes also an increase in magnitude of the SST variability, decrease of the wind speed and the latent heat flux in the wake of a CCKW trajectory. For example, areas around 70E and 98E were affected by decrease in the diurnal SST variability due to CCKW passage and subsequent increase in magnitude of the diurnal SST variability in the wake of the disturbance. Such variability in magnitude of the upper ocean temperature can be seen in Fig. 8 where the areas of interest are marked with red ellipses. In the wake of ' $\mathrm{KW} 1$ ' wave, at the longitude $71 \mathrm{E}$, the diurnal SST variability increases. Similarly, in the wake of $\mathrm{KW} 2$, at the longitude $98 \mathrm{E}$, the upper ocean temperature diurnal cycle is increased. Location, timing and persistence of the increased values of the diurnal SST variability agrees well with the area and time of the origin of the second (KW 2) and the third (KW 3) of the 3 consecutive CCKWs. Initiation of the second wave, which took place on January 29 at $70 \mathrm{E}$, occurred in the area where the 
diurnal SST variability, wind speed, latent heat flux at the ocean surface increased. Moreover, such increase in the wind speed and the latent heat flux at this time and location seems to form a slow moving, westward propagating disturbance. The origin of this disturbance may be tracked back to the strong wind speed and latent heat flux anomalies at 95E on January 27, associated with the first (KW 1) of the three consecutive CCKW. These interactions can be seen in Figs. 9 and 10 which present wind speed and latent heat flux at the ocean surface for the investigated period. The area where the second (KW 2) originated was affected by a local thermodynamic (increased SST variability) anomaly and a propagating dynamic anomaly (i.e. increased wind speed and latent heat flux). Both of these anomalies may have been induced by the first of the consecutive waves (KW 1) and this supports the idea of forcing of the sequential CCKW (KW 2) by preceding event. A local thermodynamic forcing, in the wake of a moving convective disturbance, is likely associated with the area of subsidence surrounding the area of deep convection (Kiladis et al. 2009). When convective part of a CCKW leaves the area it is followed by environmental conditions with high insolation and weak wind speeds at the ocean surface (Flatau et al. 1997). Such environmental conditions favor development of a strong diurnal cycle of temperature in the upper ocean (Baranowski et al. 2016).

Based on numerical experiments (Ferreira et al. 1996) it was shown that a Kelvin wave activity is often associated with formation of an off equatorial circulation in the form of a Rossby wave. Such disturbances propagate westward and are associated with a westerly wind burst. Although circulation and convection associated with Rossby wave is mostly off equatorial (Kiladis et al. 2009), and cannot be tracked using a database used in this study, its signature can be seen in the wind speed and latent heat flux signals within the equatorial belt. Westward propagation of increased dynamic signal prior to the formation of the second (KW 2) of the three consecutive CCKWs suggests that interaction with Rossby wave can be responsible for its initiation.

Analysis of fluxes and their variability at the area of origin of the third (KW 3) of the consecutive CCKWs shows that the wind speed and the latent heat fluxes were small during its initiation. However, the magnitude of the diurnal SST variability was large just before formation of the ' $\mathrm{KW}$ 3 '. It can be traced back to an increased magnitude of the diurnal SST between longitudes 80E and 100E in the wake of KW 2. In this case there is no indication of the dynamic interaction with the preceding CCKW because the wind speed and the latent heat fluxes are relatively small.

Another interesting spin off case was observed during the DYNAMO project timeframe. In November 2011 during the DYNAMO field campaign (Yoneyama et al. 2013) an MJO event was observed and intensively studied. Two sequential CCKWs were embedded in that MJO event's convective envelope (Baranowski et al. 2016; DePasquale et al. 2014; Gottschalck et al. 2013; Johnson and Ciesielski 2013). The second of the sequential CCKWs initiated at 55E on November 26 (Baranowski et al. 2016) and within 1 day intensified and exceeded 3 standard deviations of CCKW filtered precipitation [see Table 2 in Gottschalck et al. (2013)]. Initiation and intensification occurred in the area affected by the equatorial Rossby wave induced westerly wind burst (see for example an analysis of $925 \mathrm{mb}$ winds from India Meteorological Department WFR model for 27 November 2011 in the DYNAMO EOL catalog ${ }^{1}$ ). The cyclonic circulations associated with this Rossby wave developed in relation to the first of the sequential CCKWs which passed over the longitude 75E on November 24 (Johnson and Ciesielski 2013) and by November 27 approached the Maritime Continent (Baranowski et al. 2016). These conditions suggest that the spin off initiation of the second of the sequential CCKWs occurred in November 2011 MJO. This analysis provides another example of a spin off initiation but it is an alternative to the explanation provided by Kerns and Chen (2013) who considered both CCKWs in November 2011 to be the part of one system separated by a dry air intrusion related to the Rossby gyres.

In summary, we have shown that a CCKW can develop in a wake of another CCWK. The sequential CCKW initiation can be linked to enhanced diurnal SST in the subsiding part of a preceding CCKW (KW3) or dynamically increased surface fluxes (KW2 and DYNAMO case study). The latter is consistent with other studies showing favorable conditions for cyclonic circulation development in a wake of a CCKW (Schreck 2016), in particular over the Indian Ocean 2 days after a CCKW passage (Schreck 2015). In both cases we call this process a spin off. The preceding (spinning) wave influences the environment in its proximity and the sequential (spin off) wave develops. Analysis shows that the interaction between a preceding wave, and the environment where spin off wave develops, may rely on both the dynamic and local thermodynamic forcings. The dynamic forcing, which includes propagation of an area of the increased wind speed and latent heat fluxes, is likely related to the Rossby wave. A local thermodynamic forcing is due to the increased diurnal SST variability in the wake of the preceding CCKW. In the subsequent section, on the basis of a multiple year composite analysis, we will show that such spin off initiations are common and indeed rely on both dynamic and local thermodynamic forcing.

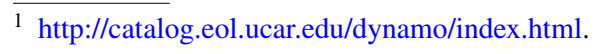


Fig. 12 Zonal distribution of number of Kelvin waves initiations. The $x$-axis is longitude in $(\operatorname{degE})$; the $y$-axis is count of Kelvin wave initiations over each $10^{\circ}$ wide area. Blue line indicates number of all Kelvin wave initiation; red line indicates number of multiple initiation Kelvin waves; green line indicates number of spin off initiation Kelvin waves. Black line indicates sum of multiple and spin off initiations at each longitude

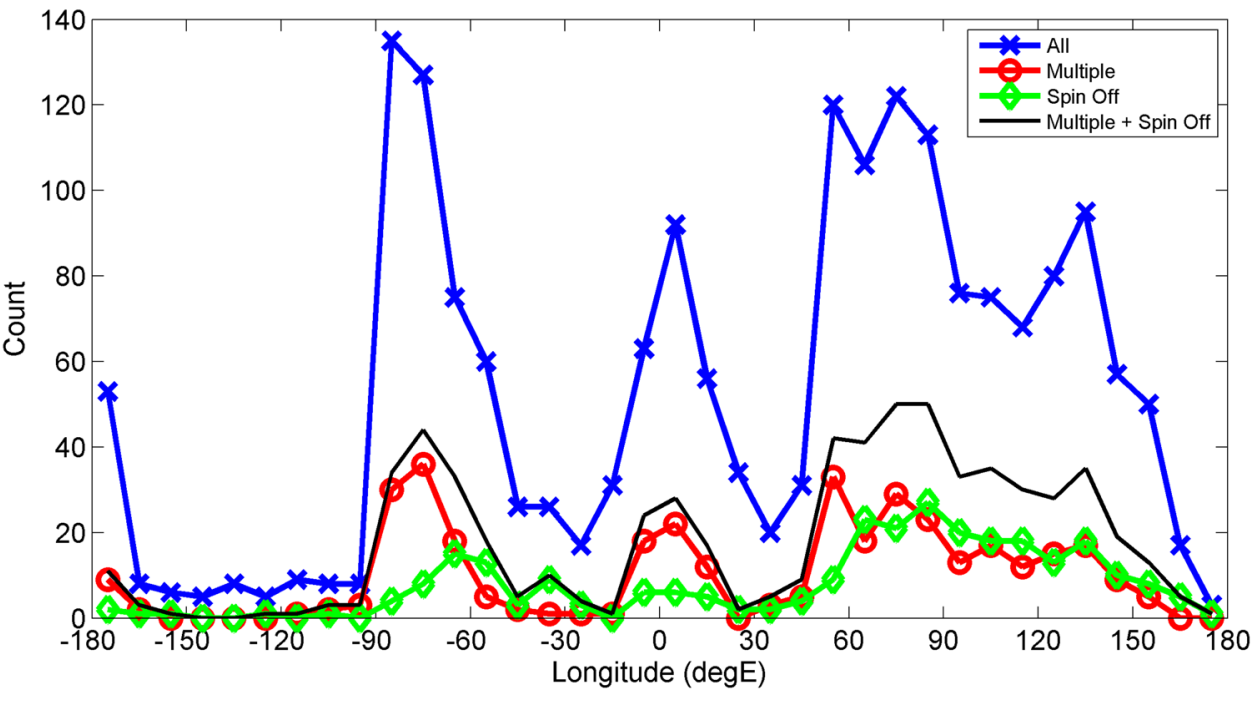

\section{Composite analysis of initiation of CCKW}

It can be seen (Fig. 1) that CCKWs activities differ between various regions. The zonal variability is strongest for the CCKWs, which occur within a short time period after each other. Such events have the highest chance to be part of either a multiple initiation or a spin off initiation category. In this section composite statistics of the CCKWs initiations are investigated. We use CCKW trajectory database to detect all trajectories that satisfy either one of the two categories. Multiple initiations occur when two or more CCKW trajectories initiate in the same area within a short period of time. As an example, if one CCKW initiates at $60 \mathrm{E}$ at day 0 and the other CCKW began at 63E 4 days later, they both would be considered as multiple initiations. Spin off initiations occurs when a CCKW initiates in the area over which another CCKW propagated few days earlier. As an example, if a CCKW initiates at $87 \mathrm{E}$ at day 0 , and over that location another CCKW propagated 3 days earlier, such initiation would be considered spin off initiation. Multiple and spin off initiation categories are not overlapping, i.e. a CCKW initiation can not be classified as multiple and spin off at the same time.

Globally there were 362 CCKW trajectories that satisfy multiple initiation criteria and $277 \mathrm{CCKW}$ that matched spin off initiation criteria. This means that about $20 \%$ of all CCKW are multiple initiation and about $15 \%$ of all CCKW are spin off initiation trajectories. It can also be seen, that Indian Ocean basin has the largest number of CCKWs which follow each other within a short (i.e. $<10$ days) time period. The total number of multiple CCKW initiation cases for the Indian Ocean basin is 126, which means that about $21 \%$ of all CCKWs initiated over the Indian Ocean matched the multiple initiation criteria. The total number of spin off CCKWs initiation cases for Indian Ocean basin is
106 , that is about $18 \%$ of all CCKWs initiated over Indian Ocean matched multiple initiation criteria. Together, multiple initiations and spin off initiations, account for almost $40 \%$ of all CCKWs initiation case over the Indian Ocean basin.

Figure 12 presents zonal distribution of total number of CCKW initiations, which occurred within $10^{\circ}$ wide zonal box. It can be seen that both multiple initiation and spin off initiation categories follow the zonal distribution of all CCKWs initiations. However, maximum number of spin off initiations tends to occur further to the east than the maximum number of multiple initiations. For example, in the Indian Ocean basin, the multiple CCKWs have maximum number of initiations between longitudes $50 \mathrm{E}$ and $60 \mathrm{E}$ and spin off CCKWs have maximum number of initiations between longitudes $80 \mathrm{E}$ and 90E. The Indian Ocean basin is characterized by the largest fraction of multiple and spin off initializations compared to the total number of CCKW initialization.

Figures 13, 14 and 15 present a composite analysis of the magnitude of the diurnal SST variability, wind speed and latent heat flux at the ocean surface during the CCKW initiations. Each of the figures consists of three composites: (a) is for all CCKW initiations, (b) is for multiple CCKW initiations only, and (c) is for spin off CCKW initiations only. CCKWs that initiate between longitudes $60 \mathrm{E}$ and $100 \mathrm{E}$ are used in composite calculations. The $\mathrm{x}$-axis on each panel represents the longitude relative to the longitude of a CCKW initiation and the y-axis represents the time relative to the date of a CCKW initiation.

Figure 13 presents a comparison of magnitude of the upper ocean temperature diurnal cycle in the proximity of the CCKW initiation. The composite for all CCKWs (a) shows decreased SST variability between longitudes 0 and 4 in the proximity of the time of initiation (time $=0$ days). 

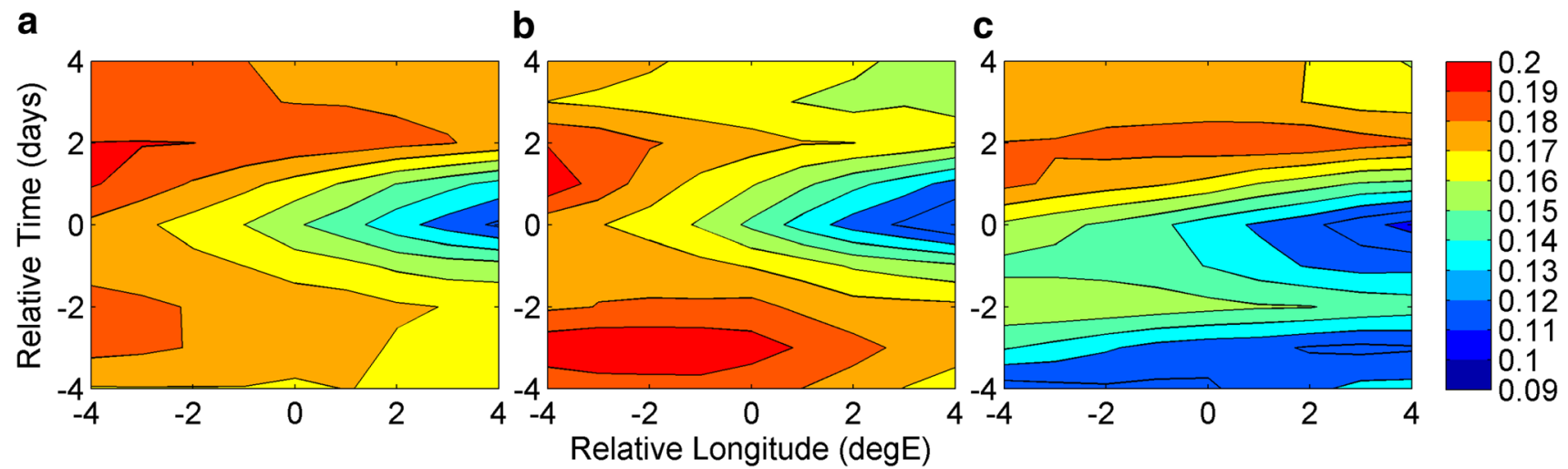

Fig. 13 The composite of the upper ocean temperature diurnal cycle in $\left({ }^{\circ} \mathrm{C}\right)$ (color shading) over the area between longitudes $60 \mathrm{E}$ and 100 E during a all Kelvin waves initiations; b multiple Kelvin wave initiations; c spin off Kelvin wave initiations. In each panel the $x$-axis

in longitude in (degE) relative to the longitude of the Kelvin wave initiation and the $y$-axis is time in (days) relative to the time of the Kelvin wave initiation
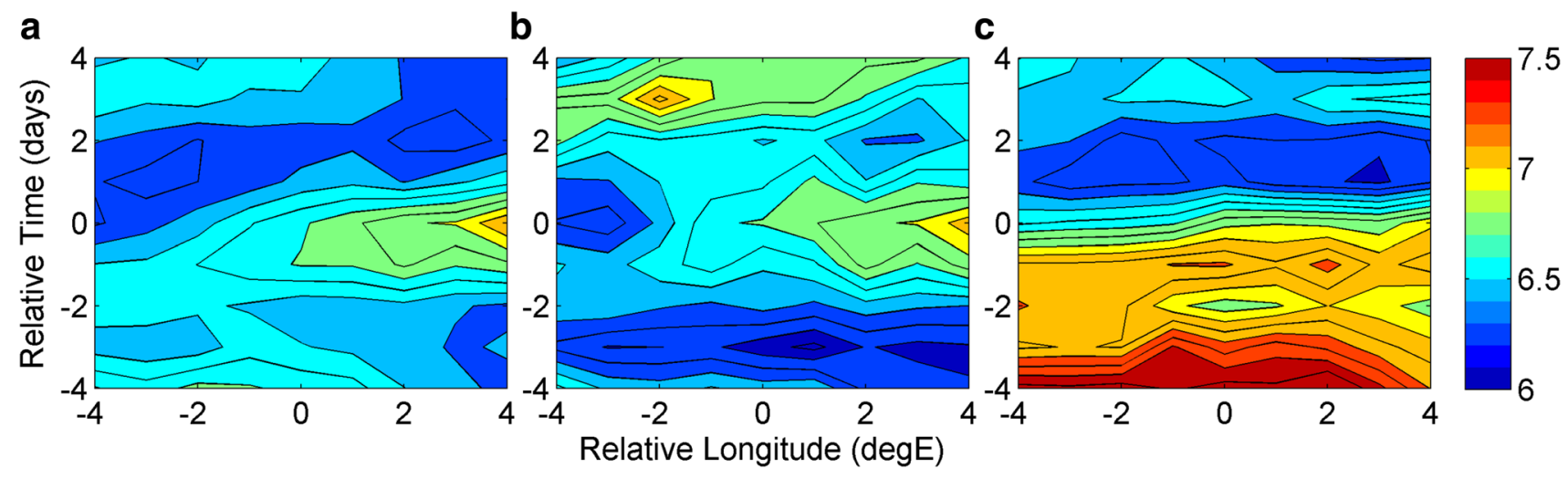

Fig. 14 Same as Fig. 13 but for the composite of the ocean surface wind speed in $\left(\mathrm{ms}^{-1}\right)$ (color shading)
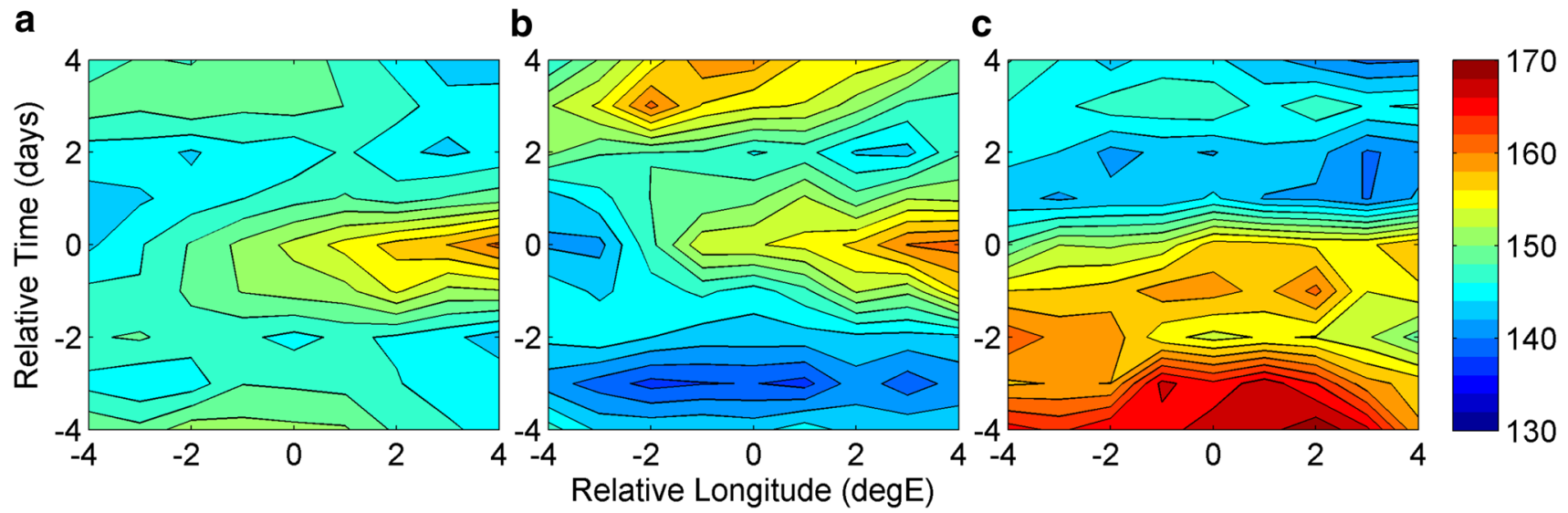

Fig. 15 Same as Fig. 13 but for the composite of the ocean surface latent heat flux in $\left(\mathrm{Wm}^{-2}\right)$ (color shading) 
This is manifestation of the initiation and passage of the CCKW that is able to suppress the upper ocean diurnal cycle. The eastward propagation is not clearly observable in Figure because we consider area limited to the vicinity of the CCKW initiation through which CCKW propagates within few hours. Since, the temporal resolution of the ocean surface data is 1 day, propagation of the CCKW appears instantaneous. However, change in the magnitude of the SST variability is consistent with the CCKW phase speed. A similar structure is present in panels (b) and (c).

There are substantial differences between the 3 panels in magnitude of the diurnal SST variability anomaly prior to the wave development. The composite (a) for all CCKW initiations shows increased diurnal SST variability 2 days prior to wave initiation and 2 days after the initiation. The maximum of the diurnal SST variability is located $3^{\circ}$ to the west in comparison with the location of a CCKW initiation. In this case, the SST variability is larger after the wave passage. Although the overall zonal and temporal structure of SST variability is reproduced in multiple initiations composite, there are differences in magnitudes. When only multiple initiations are considered, the maximum of diurnal SST variability prior to wave development is stronger and extends from the location of the initiation to the west. The magnitude of the maximum observed after CCKW passage does not change, but one can see the decrease of the magnitude of the SST variability 3 days after the initiation, which is likely due to generation of the sequential CCKW.

The spin off CCKWs displays different SST variability in comparison to all CCKWs and multiple CCKWs composites. Although the suppressed diurnal cycle due to CCKW development and propagation is still apparent, the time prior to the CCKW development is dominated by low SST variability likely related to a preceding CCKW. The increased upper ocean temperature diurnal structure is present 2 days prior to CCKW initiation, but the magnitude is much lower in comparison to previous composites. The SST variability increases 2 days after the initiation.

Figure 14 presents composites of the ocean surface wind speed for initiations of (a) all CCKWs, (b) multiple CCKWs and (c) spin off CCKWs. It can be seen in panel (a) that on average, the wind speed increases during the CCKW initiation and eastward propagation. Prior and after the initiation, the values of wind speed anomalies are lower. It is consistent with suppressed SST variability at the time of a CCKW development shown in Fig. 13. The multiple CCKW initiation composite (b) shows that the ocean surface wind speed increase at the time of wave development which is similar to the all-CCKWs composite. However, prior to the initiation, the wind speed during the multiple CCKW initiation is even lower than in the all-CCKWs composite case. The increased wind speed 3 days after the development of a CCKW event is likely due to passage of the sequential wave. Figure $14 \mathrm{c}$ shows that the wind speed increases prior to the spin off CCKW initiation. This increase is likely due to passage of the preceding wave. After the spin off CCKW development and its passage the wind speed decreases rapidly.

Figure 15 presents composites of the ocean surface latent heat flux variability associated with the initiation of (a) all CCKWs, (b) multiple CCKWs and (c) spin off CCKWs. It can be seen that zonal and temporal variability associated with each category is very similar to one shown for the wind speed variability. For (a) all CCKWs and (b) multiple CCKWs an increased latent heat flux at the time of the initiation from an area of origin to the east is apparent. For (a) all CCKWs the latent heat flux is decreased prior to and after the wave development. This decrease prior to the wave initiation is stronger when only multiple CCKWs are considered. The increased latent heat flux values are observable 2-4 days after the wave development. It is a manifestation of the sequential wave development and passage. The (c) spin off initiation is associated with large latent heat flux consistent with time and region of the strong winds.

In summary, the composite analysis of multiple initiations of CCKWs shows that prior to a wave initiation, the upper ocean temperature diurnal variability is highly increased. At the same time the ocean surface wind speed and latent heat fluxes are decreased. This implies that inhomogeneity in local thermodynamic processes (presence or lack of the diurnal warm layer) is responsible for triggering the CCKW in multiple initiation cases. It has been shown (Li and Carbone 2012) that maxima of the spatial SST gradient are related to development of atmospheric convection; our results also show that the multiple CCKWs are initiated when the diurnal SST variability is the largest.

On the other hand, the diurnal SST variability during the spin off CCKW initiations is secondary to the strong ocean surface wind speed and latent heat flux variability. Therefore, the triggering of the spin off CCKWs is likely to have strong dynamic component with some contribution from the local thermodynamic forcing.

\section{Summary and conceptual models of sequential CCKW initiation}

In this paper initiation of sequential CCKWs has been investigated on the basis of individual case studies and 15-year composites of CCKWs trajectories. We have shown that variability of the surface fluxes and the upper ocean temperature diurnal cycle plays an important role in CCKW initiations. The upper ocean temperature diurnal variability was assessed using the daily mean temperature 
Fig. 16 a Zonal section of geopotential height $(\mathrm{m})$ along the equator for control simulation 's1' (blue), varying source simulation 's2' (red) and varying source with varying amplitude simulation 's3' (green). The $x$-axis is longitude in (degE); the $y$-axis is geopotential height in (m). b Is the same as a but for zonal wind speed in $\left(\mathrm{ms}^{-1}\right)$
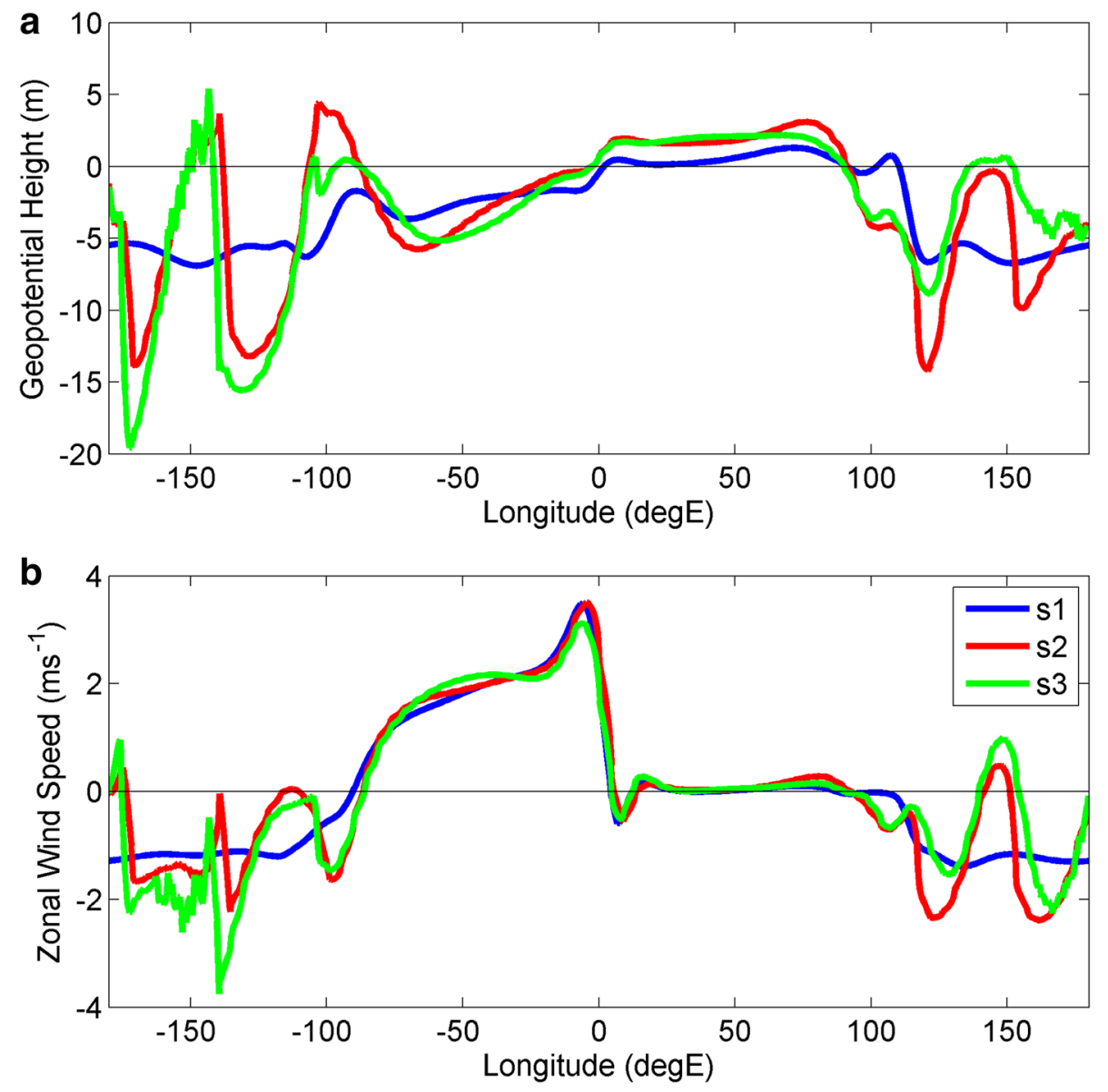

anomaly estimate (Matthews et al. 2014) which combines the wind speed and the insolation at the ocean surface.

We noticed that sequential CCKW initiation events, which account for more than $60 \%$ of all CCKW in the Indian Ocean, may be divided into two distinct categories: multiple initiations and spin off initiations. A multiple initiation occurs when two or more CCKWs develop over the same area within a short time period. The spin off initiation happens when a CCKW develops in the wake of another CCKW. In this section we develop conceptual models of sequential waves initiations. These models highlight key processes responsible for development of CCKWs of multiple and spin off categories.

\subsection{A conceptual model of multiple initiations and shallow water model results}

To provide a theoretical understanding of processes underlying multiple initiations of CCKWs we begin with simple numerical modeling set up which is described in more detail in the Appendix. In short, we have used a diurnally varying heat source in the shallow water model to mimic the upper ocean temperature diurnal cycle influence on a dry Kelvin wave initiation. We contrast these oscillating source simulations with a control simulation in which the source is constant in time. Also, we performed simulations in which the amplitude of the oscillations is varied. While most of the discussion is confined to the Appendix here we provide the main motivational results.

Figure 16 presents a comparison of (a) geopotential height and (b) wind speed on the equator between control run (s1) and varying source simulations (s2 for constant amplitude of oscillations and s3 for varying amplitude of oscillations). Comparison of all three simulations shows that the differences in temporal distribution of the heat source do not affect Rossby wave response but Kelvin wave response to the temporally disturbed heat source shows significant differences. A sequence of maxima and minima in the geopotential height and wind speed represent spatial structure of sequential Kelvin waves. This result shows that the magnitude of negative geopotential height anomaly associated with the second $(-130 \mathrm{E})$ and the third $(-170 \mathrm{E})$ Kelvin wave is larger in 's3' simulation than in 's2' simulation. On the other hand, the forth (155E) and fifth (120E) waves in Kelvin wave sequence have smaller negative geopotential height anomaly in simulation ' $s 3$ ' than in experiment 's2'; that means that the amplitude of a Kelvin wave depends on source amplitude from which it originated. The 


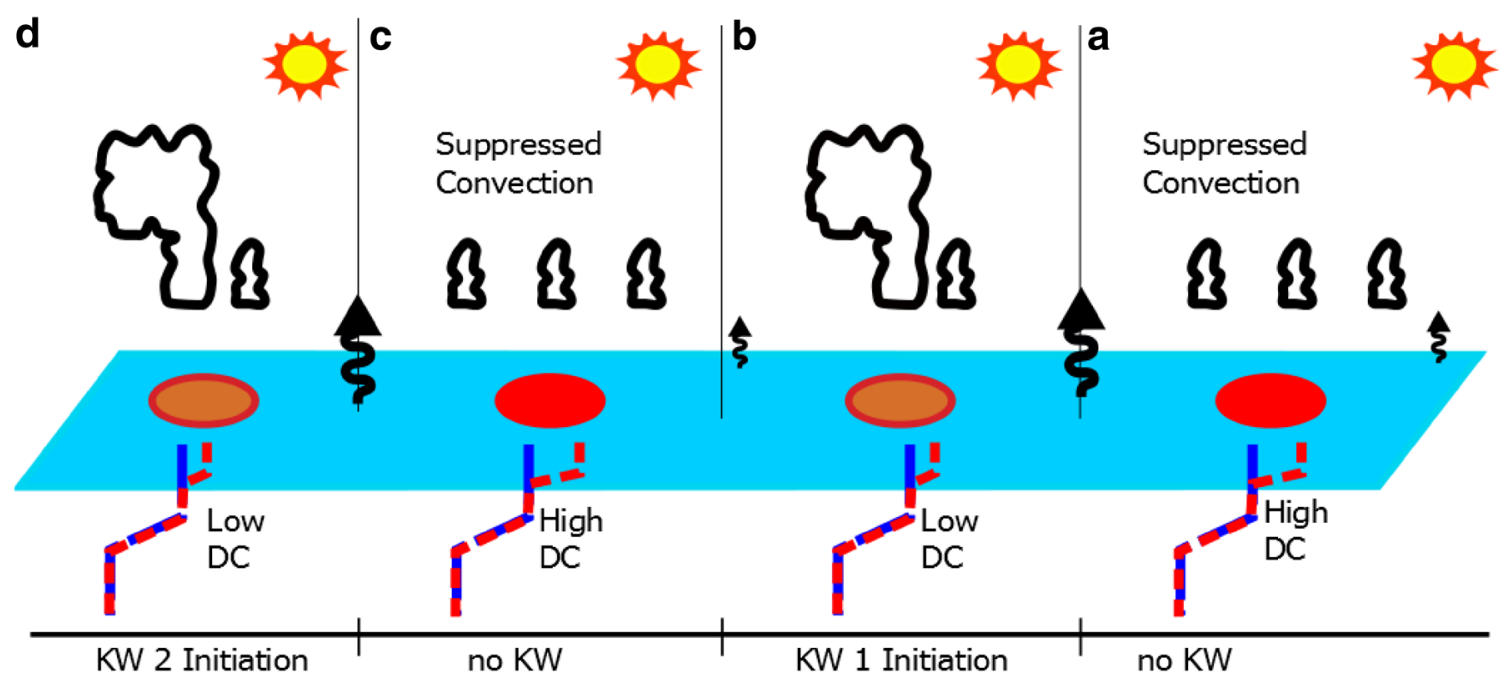

Fig. 17 A conceptual model of multiple Kelvin wave initiation: a and $\mathbf{c}$ represent conditions of suppressed atmospheric convection with high insolation, weak winds and strong diurnal cycle development, b and $\mathbf{d}$ represent days of Kelvin wave initiation preceded by increased air-sea fluxes due to warm layer development

to directly heat the atmosphere and influence convection development (Ruppert 2016; Ruppert and Johnson 2016). Furthermore, shallow water model solutions suggest that the link between short-term variability of a source and a structure of Kelvin wave response is truly nonlinear and exemplifies interactions across many temporal and spatial scales. Such multi-scale interactions have been shown to be an important component of intraseasonal variability (Neale and Slingo 2003; Oh et al. 2013; Peatman et al. 2014; Ruppert 2016; Yang and Majda 2014). Aspects of nonlinear interaction between local diurnal cycle and organized convection in the tropical atmosphere should be further investigated in a modeling framework.

Finally, Fig. 17 summarizes the key characteristics identified in case studies and composites of multiple CCKWs initiation as well as that of modeling. In presence of the suppressed atmospheric convection the upper ocean temperature diurnal cycle is high and, as a result, the air-sea fluxes are high (see Fig. 17a, c). This leads to development of a CCKW on the following day (see Fig. 17b, d). When a CCKW initiates, the diurnal cycle is weaker in comparison to preceding days but it is not suppressed completely. The day-to-day variability of the magnitude of the upper ocean temperature diurnal cycle forces variability of the oceanic fluxes. However, on a day that exhibits a warm layer development, the air-sea fluxes response is delayed in comparison to the SST response. This is because the energy storage in the warm layer which lasts into the night and enables anomalous flux after the sunset (Matthews et al. 2014). In this conceptual model we assume that the atmospheric heating source driving the atmospheric convection is tied to the upper ocean temperature diurnal variability. 
Fig. 18 A conceptual model of spin off Kelvin wave initiation. At Time 1 the mature Kelvin wave (KW 1), which suppresses upper ocean diurnal cycle, is at Longitude 1. At Time 2 this wave moves eastward and in its wake high diurnal cycle develops at Longitude 1. At Time 3 an off equatorial circulation develops at Longitude 2 which results in observable wind speed increase on the Equator. The circulation strengthens while propagating westward and enhances surface fluxes via wind burst induced evaporation, which forces a spin off Kelvin wave (KW 2) at Longitude 1 at Time 4. This mechanism describes KW1-KW2 "dynamical" spin off

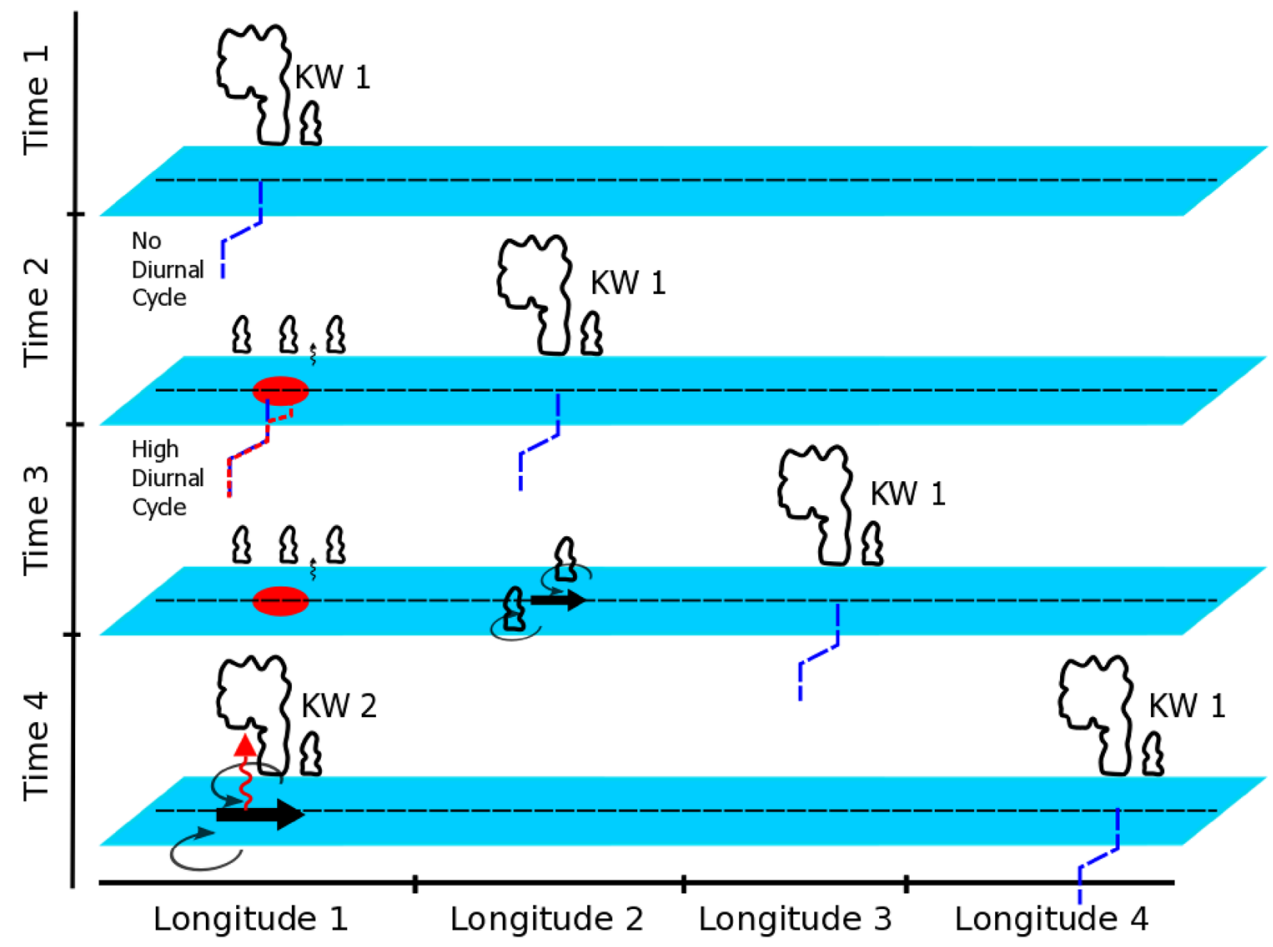

\subsection{Conceptual model of spin off initiation}

Sequential CCKWs belonging to the spin off category are forced by interaction with the preceding CCKW. Figure 18 summarizes the key characteristics identified in case studies as well as composite analysis of the spin off initiation of CCKWs. The preceding (spinning) CCKW suppresses the diurnal SST variability due to high cloud cover and strong winds (Flatau et al. 1997). On the following days it moves eastward, the convection is suppressed and wind speed is low which results in strong upper ocean diurnal temperature cycle in its wake (Baranowski et al. 2016). While the preceding CCKW moves further east, it may help in formation of the off equatorial circulation (Schreck 2015, 2016) manifested by increased wind speed at the equator. Dynamical signal associated with this off equatorial circulation strengthens while propagating westward and increases energy flux from the ocean to the atmosphere via wind burst over high SST region. This results in spin off CCKW initiation.

\footnotetext{
Acknowledgements DBB has been supported by the Office of Naval Research Global NICOP program (award N62909-15-1-2021 to the University of Warsaw). MKF has been supported by the Chief of Naval Research through the NRL Base Program, PE 0601153N, PJF has been supported by Naval Research Laboratory grant "Atmospheric Processes in Coupled Ocean-Atmosphere Systems" and JMS has been supported by NRL Base Program, PE0601153N ("Equatorially Trapped Moist Modes"). Development of the Kelvin wave trajectories database has been supported by Poland's National Science Centre (Narodowe Centrum Nauki; decision no. 2012/07/N/ST10/03303).
}

Analysis of the DYNAMO field campaign data have been supported by the Office of Naval Research under Program Element 601153N. The global ocean heat flux and evaporation products were provided by the WHOI OAFlux project (http://oaflux.whoi.edu) funded by the NOAA Climate Observations and Monitoring (COM) program. The TropFlux data is produced under a collaboration between Laboratoire d'Océanographie: Expérimentation et Approches Numériques (LOCEAN) from Institut Pierre Simon Laplace (IPSL, Paris, France) and National Institute of Oceanography/CSIR (NIO, Goa, India), and supported by Institut de Recherche pour le Développement (IRD, France). TropFlux relies on data provided by the ECMWF Re-Analysis interim (ERA-I) and ISCCP projects.

Open Access This article is distributed under the terms of the Creative Commons Attribution 4.0 International License (http:// creativecommons.org/licenses/by/4.0/), which permits unrestricted use, distribution, and reproduction in any medium, provided you give appropriate credit to the original author(s) and the source, provide a link to the Creative Commons license, and indicate if changes were made.

\section{Appendix: shallow water modeling}

In this Appendix a shallow water model will be used to investigate impact of the shortterm variability of a source on the tropical atmosphere. Such shallow water models on the equatorial beta plane have been used to study impacts of the heat source spatial and temporal characteristics on the tropical waves response (Silva Dias et al. 1983; Silva Dias et al. 1987). It has been shown that such diurnal variability of the localized forcing is important for the equatorial flow 
over the Amazonia region and that the amount of energy of the Kelvin wave response is larger for the rapid heat source. Similar approach has been used to study atmospheric equatorial perturbations generated by extratropical transient forcing (Zhang and Webster 1992). Here, we use a similar approach to study influence of the diurnal variability of the heat source located on the Equator on the spatial and temporal structure of dry Kelvin waves. In our analysis both constant and varying heat sources will be considered. Additionally, we investigate implications of the day-to-day variability of the oscillating heat source by introducing variable amplitude of the daily pulses.

\section{Shallow water model description and simulation set up}

Hypothesis that the diurnal cycle and its characteristics may impact structure of the equatorial Kelvin waves is tested using global, two-dimensional spectral element shallow water model (Giraldo 2000). This model solves shallow water equations on a spherical geodesic grid. It is suitable for testing a dynamic response of the global atmospheric circulation to the prescribed and idealized forcing. The equations are solved for the four variables $\varphi, \varphi \mathrm{u}, \varphi \mathrm{v}$ and $\varphi \mathrm{w}$, where $\varphi$ is a geopotential, $\mathrm{u}, \mathrm{v}$ and $\mathrm{w}$ are velocity components. Forcing consists of the force due to pressure $\left(\mathbf{F}_{\mathrm{P}}\right)$, the force due to the rotation of the earth $\left(\mathbf{F}_{\mathrm{R}}\right)$, the force required to constrain that the fluid particles remains on the surface of the sphere $\left(\mathbf{F}_{\mathrm{C}}\right)$ and additional mass source/sink, which represents external forcing $\left(\mathbf{F}_{\mathrm{F}}\right)$

$$
\frac{\partial \varphi}{\partial t}+\nabla \cdot(\varphi \mathrm{u})=\mathrm{S}(\varphi)
$$

$$
\begin{aligned}
\varphi & =\left[\begin{array}{c}
\varphi \\
\varphi u \\
\varphi v \\
\varphi w
\end{array}\right], \mathrm{u}=\left[\begin{array}{c}
u \\
v \\
w
\end{array}\right], \mathrm{S}(\varphi)=\mathrm{F}_{P}+\mathrm{F}_{R}+\mathrm{F}_{C}+\mathrm{F}_{F}, \mathrm{~F}_{P} \\
& =-\varphi \nabla \varphi, \mathrm{F}_{R}=-f(\mathrm{r} \times \varphi \mathrm{u}), \mathrm{F}_{C}=\mu \mathrm{r}
\end{aligned}
$$

where $\mathrm{f}$ is the Coriolis parameter and $\mu$ is the Lagrange multiplier used to constrain the fluid particles to remain on the surface of the sphere condition. Numerical experiments were conducted using different temporal characteristics of the external forcing term $\mathbf{F}_{\mathbf{F}}$.

Hexahedral model grid was used in all simulations. The horizontal resolution is roughly equivalent to the grid point resolution of $2.2^{\circ}$. This model has no explicit momentum damping. Thus, the Kelvin wave solution is not damped and they are able to propagate along the entire equator. Once a wave approaches the heat source it further interacts with it, which produces complex spatial pattern.
All runs were conducted using mass sink of a circular shape centered at the equator at longitude and latitude $[0,0]$ (Ferreira et al. 1996). The source had constant spatial distribution with radius equivalent to $10^{\circ}$ along the equator. Elsewhere $\mathbf{F}_{\mathrm{F}}$ value was set to 0 . Equation

$F_{F}=\left\{\begin{array}{cc}f(t), & r \leq 10 \text { degrees } \\ 0, & r>10 \text { degrees }\end{array}\right.$

defines the spatial distribution of external forcing where $f(t)$ refers to temporal variability of mass sink described by Eq. (1.4) and $r$ is distance from the source center, time is in days, $T$ is period of oscillation set to $24 \mathrm{~h}$, and $\tau$ is the source amplitude. The atmosphere is initially at rest, thus developing flow is directly forced by the source. Length of the simulation was always 10 days. External forcing had non-zero value during the first 5 days of the simulation. Equation

$$
f(t \leq 5)=\left\{\begin{array}{l}
s 1: \tau \\
s 2: \tau\left[1+\sin \left(\frac{2 \pi}{T} t\right)\right] \\
s 3: \tau\left\{1+\sin \left(\frac{2 \pi}{T} t\right)-0.5 \cdot \frac{2}{\pi} \cdot \arctan \left[\left(\frac{t}{T}-2.5\right) \cdot 10\right]\right\}
\end{array}\right.
$$

describes temporal characteristic of the mass sink for the first 5 days; 's1' refers to the constant forcing experiment, 's2' refers to the case of forcing that oscillates with period $\mathrm{T}$ equal 1 day and constant magnitude $\tau$ and 's3' refers to the case with forcing oscillating with period $\mathrm{T}$ and magnitude changing with time. The arctan function in 's3' forcing has been chosen so that for the first 2.5 days of simulation the magnitude is $2.5 \tau$ and for the later 2.5 days it is $1.5 \tau$ which simulates variation in an amplitude of the oscillating source. Integrated external forcing is the same for all simulations.

\section{Results}

Figure 19 presents control simulation ' $\mathrm{s} 1$ ' at 7.75 days when the edge of a Kelvin wave propagated around the equator and approached the area where it had been initiated. In this simulation Kelvin wave, Rossby wave and their interactions are apparent. Kelvin wave response is manifested by negative geopotential height anomaly west of longitude $-100 \mathrm{E}$ (this is relative longitude as these are aqua-planet simulations). After 7.75 days Kelvin wave travelled eastward along the equator and its leading edge is visible at longitude $-100 \mathrm{E}$ (Kelvin waves propagate to the east). The Rossby wave response is manifested as a pair of symmetric cyclonic gyres at $[15 \mathrm{~N},-50 \mathrm{E}]$ and $[-15 \mathrm{~N},-50 \mathrm{E}]$ and is associated with the pair of positive geopotential height anomalies at $[20 \mathrm{~N},-20 \mathrm{E}]$ and $[-20 \mathrm{~N},-20 \mathrm{E}]$. The equatorial area between the two Rossby gyres and between longitudes $-87 \mathrm{E}$ and $3 \mathrm{E}$ is 


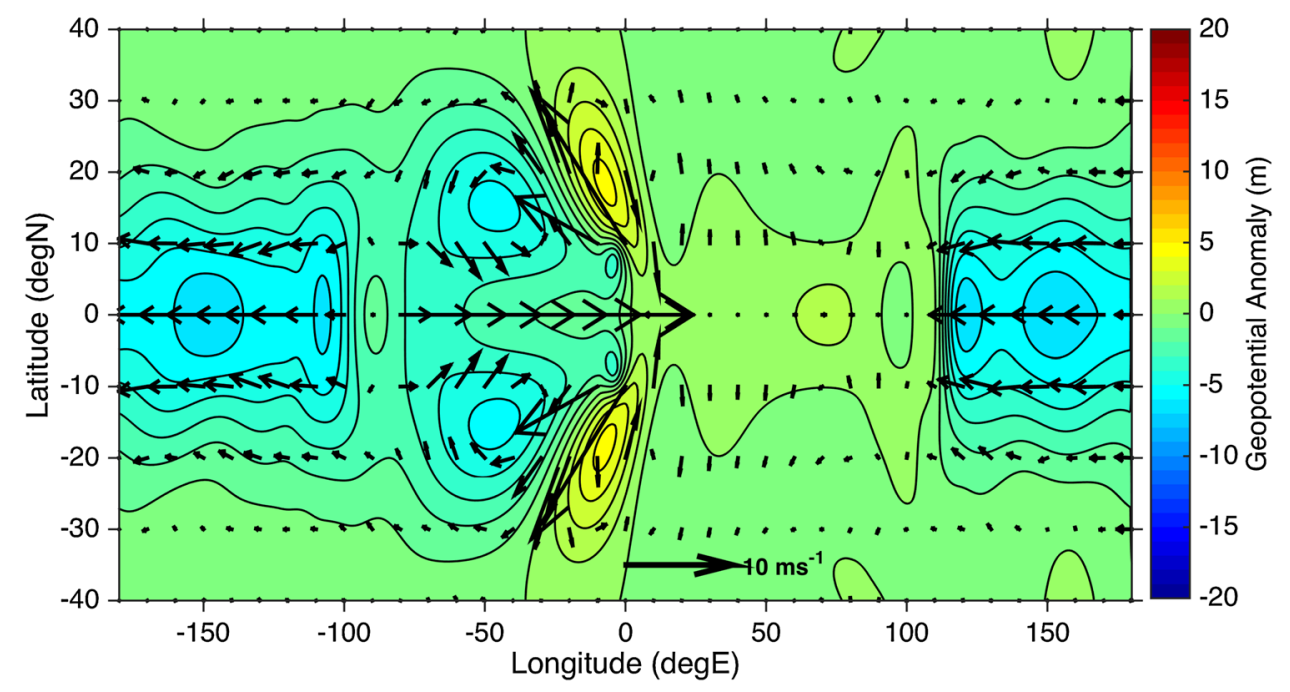

Fig. 19 Constant heat source experiment 's1' (control) at 7.75 days. The $x$-axis is longitude in (degE); the $y$-axis is latitude. Color shading indicates geopotential anomaly in (m) and arrows indicate wind anomaly in $\left(\mathrm{ms}^{-1}\right)$. The heat source is located at $[0,0]$ and has $10^{\circ}$ spatial extent. At $[20 \mathrm{~N},-20 \mathrm{E}]$ and $[-20 \mathrm{~N},-20 \mathrm{E}]$ are positive geopotential anomalies associated with Rossby wave. Negative geo- potential anomaly between longitudes $100 \mathrm{E}$ and $-100 \mathrm{E}$ is related to Kelvin wave response, which was initiated at the heat source location and circulated around the globe. Westerly wind burst can be seen at $[-50,0]$ close to equator and it is related to Kelvin wave and Rossby wave interaction

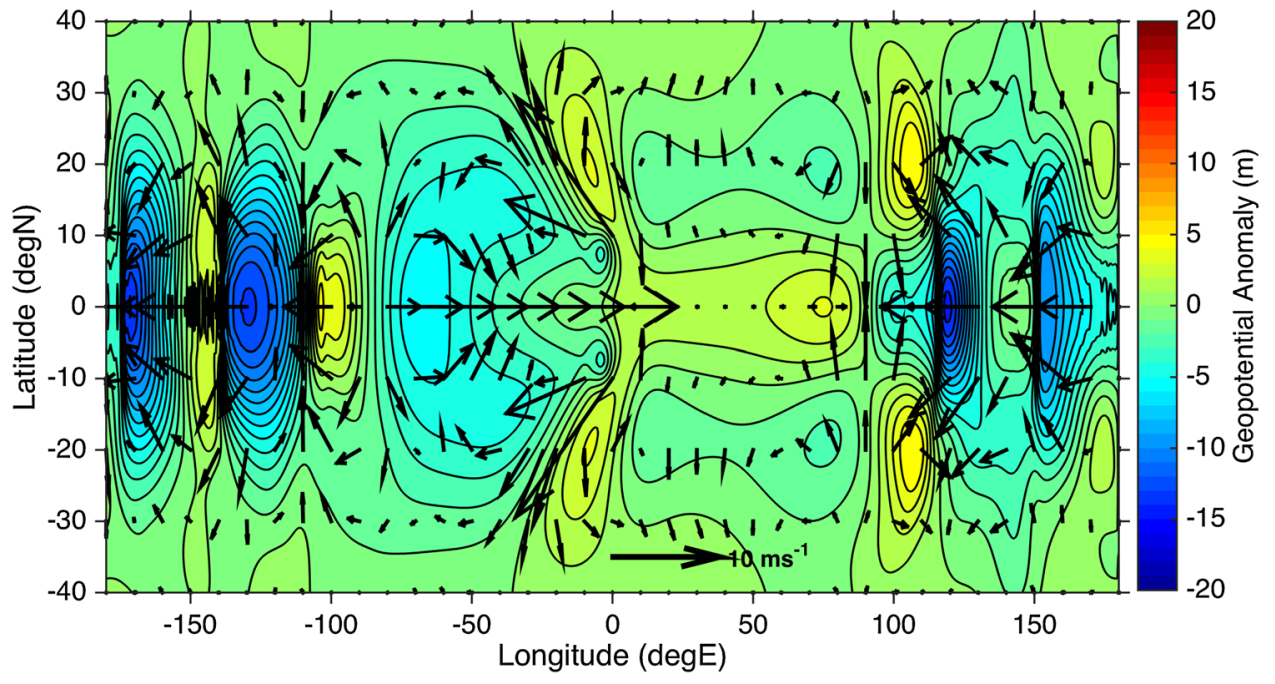

Fig. 20 Varying heat source with constant amplitude experiment 's2' at 7.75 days. The $x$-axis is longitude in (degE); the $y$-axis is latitude. Color shading indicates geopotential anomaly in (m) and arrows indicate wind anomaly in $\left(\mathrm{ms}^{-1}\right)$. The heat source is located at $[0,0]$ and has $10^{\circ}$ spatial extent. At $[20 \mathrm{~N},-20 \mathrm{E}]$ and $[-20 \mathrm{~N},-20 \mathrm{E}]$ are positive geopotential anomalies associated with Rossby wave. Sequence of negative geopotential anomalies west of longitude -25 are related to Kelvin waves which were initiated at the heat source location and

associated with westerly wind anomaly. After 7.75 days the edge of the Kelvin wave interacts with the Rossby wave. The area between $-100 \mathrm{E}$ and $-87 \mathrm{E}$ is characterized by shift in zonal flow from easterly to the west of that location to westerly to the east of that location. circulated around the globe. Strong westerly wind burst can be seen at between $[-50,0]$ close to equator and it is related to Kelvin wave and Rossby wave interaction. Westerly bursts can also be seen at longitudes $-110,-150$ and 150 , and are related to sequential Kelvin waves interaction. Between longitudes 100 and 150 the structure consisting of two negative and two positive geopotential anomalies is associated with Westerly Inertial Gravity wave

Control simulation shows differences in phase speed between Kelvin and Rossby wave responses. In 7.75 days Kelvin wave almost travelled around the entire equator and Rossby wave travelled a distance of $50^{\circ}$. 


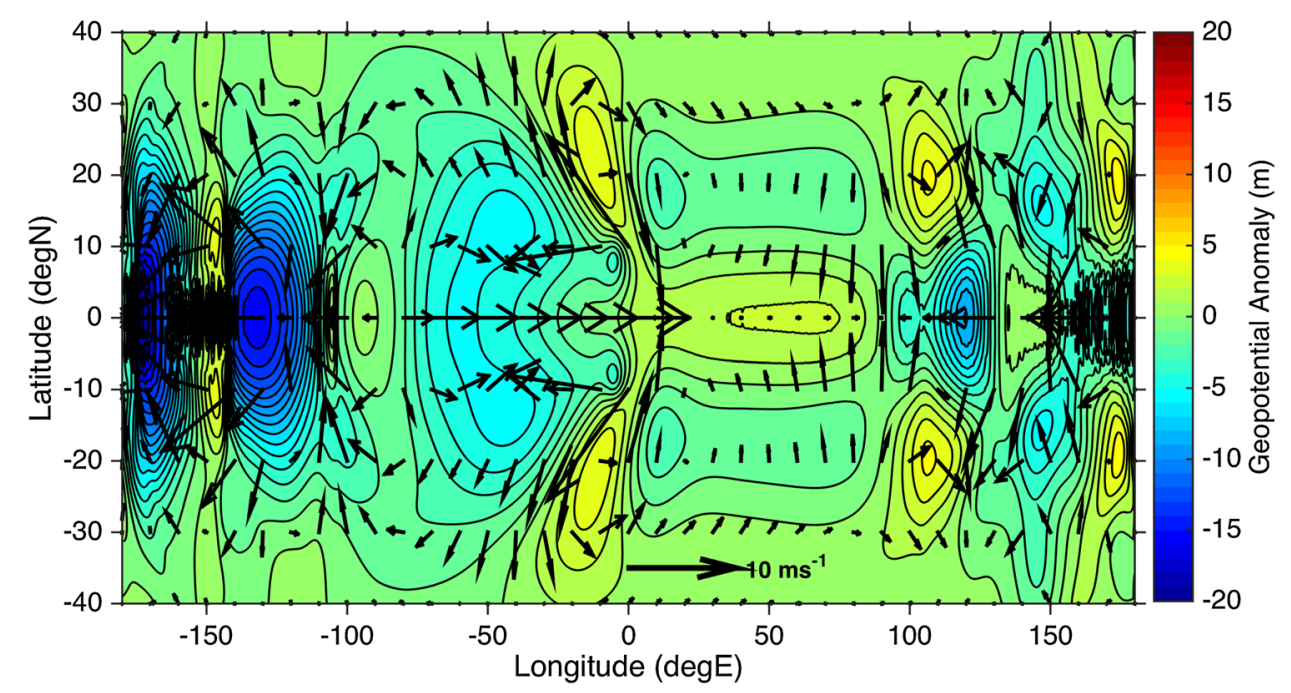

Fig. 21 Varying heat source with varying amplitude experiment 's3' at 7.75 days. The $x$-axis is longitude in $(\operatorname{degE})$; the $y$-axis is latitude. Color shading indicates geopotential anomaly in (m) and arrows indicate wind anomaly in $\left(\mathrm{ms}^{-1}\right)$. The heat source is located at $[0,0]$ and has $10^{\circ}$ spatial extent. At $20 \mathrm{~N}$ and $20 \mathrm{~S}$ are positive geopotential anomalies associated with Rossby wave. Sequence of negative geopotential anomalies west of longitude -25 are related to Kelvin waves which were initiated at the heat source location and circulated

Figures 20 and 21 show results for experiments 's2' and 's3'. It can be seen that Rossby wave response does not change much in comparison with the simulation ' $s 1$ ' but structure of the Kelvin wave response is different. In simulation 's2' the air flow and the geopotential height structure is different from the control simulation at longitude $-60 \mathrm{E}$ where geopotential height minimum is present at the equator. This minimum is the first of the sequence of five geopotential height minima associated with Kelvin wave responses which exhibits highly complex structure in comparison with the control simulation. A sequence of negative geopotential height anomalies along the equator with minima at longitudes $-70 \mathrm{E},-130 \mathrm{E},-170 \mathrm{E}, 155 \mathrm{E}$ and 120 E represent Kelvin waves caused by several oscillations of varying heat source. Each of the Kelvin waves is associated with easterlies on the equator along with the geopotential height minima and weak westerlies at each wave leading edge. Therefore, the dynamic structure of the Kelvin wave sequence results in shift from westerlies to easterlies at the beginning of the wave and change from easterlies to westerlies at its end. Thus, the leading edge of each wave is associated with flow divergence and the end of the wave is characterized by flow convergence.

The westerlies are associated with each of the consecutive Kelvin wave leading edge within the sequence. For the first wave in the sequence the westerlies are strong due to the interaction with the Rossby wave induced flow. Sequential westerlies are visible at longitudes $-115 \mathrm{E},-140 \mathrm{E}$ and around the globe. Strong westerly wind burst can be seen at between $[-50,0]$ close to equator and it is related to Kelvin wave and Rossby wave interaction. Westerly bursts can also be seen at longitudes -110 , -150 and 150, and are related to sequential Kelvin waves interaction. Between longitudes 100 and 150 the structure consisting of two negative and two positive geopotential anomalies is associated with Westerly Inertial Gravity wave as in Fig. 20 but with smaller amplitude because varying source has smaller magnitude in this experiment

$-175 \mathrm{E}$ and $145 \mathrm{E}$. Between longitudes $50 \mathrm{E}$ and $100 \mathrm{E}$ the symmetric structure consisting of two negative and two positive geopotential height anomalies.. It is the only area where the meridional flow at the equator is visible.

It can be seen that the differences between 's2' (Fig. 20) and 's3' (Fig. 21) are relatively small when compared with the differences between these experiments and the control run. Experiment 's3' shows that the structure of the Kelvin wave is similar to the one simulated in 's2' experiment. In Fig. 21 the sequence of waves can be seen with the geopotential height minima located at longitudes $-60 \mathrm{E}$, $-130 \mathrm{E},-170 \mathrm{E}, 155 \mathrm{E}$ and $120 \mathrm{E}$. All but the first wave are at the same locations as in the simulation ' $\mathrm{s} 2$ '. Each of the consecutive waves is associated with divergence at its leading edge and convergence at its tail due to the shift in zonal wind. This is similar to behavior simulated in ' $\mathrm{s} 2$ ' experiment. Between longitudes $80 \mathrm{E}$ and $100 \mathrm{E}$ the structure consisting of two negative and two positive geopotential height anomalies is associated with the Eastward Inertia Gravity wave, but these magnitudes are smaller than in ' $\mathrm{s} 2$ ' simulation. The relative difference is attributed to relative difference in heat source magnitude between the two simulations. In simulation ' $\mathrm{s} 3$ ' the magnitude of the diurnal heat source variability is higher for the days one and two, and lower for days 4 and 5 than in experiment 's2'. Hence, the relative differences between geopotential height anomalies associated with individual Kelvin waves are likely due to differences in the heat source magnitude. 
These results show that the difference between control, constant source simulation, and either one of the oscillating source simulations is much larger than between simulations 's2' and 's3'. This suggests that the spatial pattern of a Kelvin wave is more influenced by the oscillatory character of a source than by amplitude of oscillations. However, differences in amplitude of oscillations are reflected in amplitude of the resulting short, daily Kelvin waves.

These three idealized simulations show that characteristics of the heat source may affect Kelvin wave characteristics and their spatial distribution but have very limited impact on Rossby waves. In the case of a variable source the geopotential height anomaly, the wind anomaly and the wind convergence are stronger than in control simulation. The symmetric structure in the tail of the group of Kelvin waves is due to the existence of the intertia-gravity waves in simulations with the diurnally varying source; these waves were not present in simulation 's1' with constant forcing. This is consistent with the analysis presented in Fig. $3 b$ in Wheeler and Kiladis (1999) which shows that in symmetric Outgoing Longwave Radiation power spectrum for these frequencies range Eastward Inertia Gravity and Kelvin waves coexist.

Most of the analysis is focused on the simulation results on day 7.75 when the simulated Kelvin waves already travel around the equator and reaches the heat source. The phase speed of the wave is approximately $50 \mathrm{~ms}^{-1}$, which is determined by the equivalent depth that is set as the initial model condition. We know that the CCKW sare convectively coupled and propagate with much lower phase speed of 11-24 ms ${ }^{-1}$. Nevertheless, these simulations shed qualitative light on the dynamical structure of sequential Kelvin waves forced by variable heat source.

Shallow water model does not have explicit representation of the physical processes responsible for the variability of the source, but Ruppert and Johnson (2015) have shown that the diurnal cycle of fluxes at the ocean surface may affect the diurnal evolution of atmospheric convection. Therefore, the development of the upper ocean diurnal warm layer is a plausible explanation for the diurnal variability in heat source responsible for forcing a sequence of Kelvin waves.

\section{References}

Baranowski DB, Flatau MK, Flatau PJ, Matthews AJ (2016) Impact of atmospheric convectively coupled equatorial Kelvin waves on upper ocean variability. J Geophys Res 121:2045-2059. doi :10.1002/2015JD024150

Chen SS, Houze RA (1997) Diurnal variation and life-cycle of deep convective systems over the tropical pacific warm pool. Quart J Roy Meteorol Soc 123:357-388. doi:10.1002/qj.49712353806
Chen S et al (2015) A study of CINDY/DYNAMO MJO suppressed phase. J Atmos Sci 72:3755-3779. doi:10.1175/ JAS-D-13-0348.1

DePasquale A, Schumacher C, Rapp A (2014) Radar observations of MJO and Kelvin wave interactions during DYNAMO/ CINDY2011/AMIE. J Geophys Res 119:6347-6367. doi:10.100 2/2013jd021031

Ferreira RN, Schubert WH, Hack JJ (1996) Dynamical aspects of twin tropical cyclones associated with the Madden-Julian oscillation. J Atmos Sci 53:929-945. doi:10.1175/1520-0469(1996)053<0929:DAOTTC >2.0.CO;2

Flatau M, Flatau PJ, Phoebus P, Niller PP (1997) The feedback between equatorial convection and local radiative and evaporative processes: the implications for intraseasonal oscillations. J Atmos Sci 54:2373-2386

Giraldo FX (2000) Lagrange-Galerkin methods on spherical geodesic grids: the shallow water equations. J Comput Phys 160:336-368. doi:10.1006/jcph.2000.6469

Gottschalck J, Roundy PE, Schreck CJ III, Vintzileos A, Zhang C (2013) Large-scale atmospheric and oceanic conditions during the 2011-12 DYNAMO field campaign. Mon Weather Rev 141:4173-4196. doi:10.1175/mwr-d-13-00022.1

Guo Y, Waliser DE, Jiang X (2015) A systematic relationship between the representations of convectively coupled equatorial wave activity and the Madden-Julian oscillation in climate model simulations. J Climate 28:1881-1904. doi:10.1175/ JCLI-D-14-00485.1

Haertel P, Straub K, Budsock A (2015) Transforming circumnavigating Kelvin waves that initiate and dissipate the Madden-Julian Oscillation. Q J R Meteorol Soc 141:1586-1602. doi:10.1002/ qj. 2461

Hence DA, Houze RA (2011) Vertical structure of hurricane eyewalls as seen by the TRMM precipitation radar. J Atmos Sci 68:16371652. doi: $10.1175 / 2011$ jas 3578.1

Houze RA, Wilton DC, Smull BF (2007) Monsoon convection in the Himalayan region as seen by the TRMM precipitation radar. Q J R Meteorol Soc 133:1389-1411. doi:10.1002/qj.106

Huffman GJ et al (2007) The TRMM multisatellite precipitation analysis (TMPA): quasi-global, multiyear, combined-sensor precipitation estimates at fine scales. J Hydrometeorol 8:38-55. doi: $10.1175 / \mathrm{jhm} 560.1$

Jiang X et al (2015) Vertical structure and physical processes of the Madden-Julian oscillation: exploring key model physics in climate simulations. J Geophys Res 120:4718-4748. doi:10.1002/ 2014jd022375

Johnson RH, Ciesielski PE (2013) Structure and properties of Madden-Julian oscillations deduced from DYNAMO sounding arrays. J Atmos Sci 70:3157-3179. doi:10.1175/jas-d-13-065.1

Kerns BW, Chen SS (2013) Equatorial dry air intrusion and related synoptic variability in MJO initiation during DYNAMO. Mon Weather Rev 142:1326-1343. doi:10.1175/MWR-D-13-00159.1

Kiladis GN, Wheeler MC, Haertel PT, Straub KH, Roundy PE (2009) Convectively coupled equatorial waves. Rev Geophys doi:10.102 9/2008rg000266

Kim D, (2009) Application of MJO simulation diagnostics to climate models. J Clim 22:6413-6436. doi:10.1175/2009JCLI3063.1

Knutson TR, Weickmann KM (1987) 30-60 day atmospheric oscillations: composite life cycles of convection and circulation anomalies. Mon Weather Rev 115:1407-1436. doi:10.1175/1520-0493(1987)115<1407:DAOCLC > 2.0.CO;2

Lau WKM, Waliser DE (eds) (2011) Intraseasonal variability of the atmosphere-ocean climate system 2nd edn. Springer Praxis Books, New York, p 613

Li Y, Carbone RE (2012) Excitation of rainfall over the tropical Western Pacific. J Atmos Sci 69:2983-2994. doi:10.1175/ JAS-D-11-0245.1 
Liebmann B, Kiladis GN, Carvalho LMV, Jones C, Vera CS, Blade I, Allured D (2009) Origin of convectively coupled Kelvin waves over South America. J Clim 22:300-315. doi:10.1175/2008j cli2340.1

Lin J-L et al (2006) Tropical intraseasonal variability in 14 IPCC AR4 climate models. Part I: convective signals. J Clim 19:2665-2690. doi:10.1175/JCLI3735.1

Madden RA, Julian PR (1972) Description of global-scale circulation cells in the tropics with a 40-50 day period. J Atmos Sci 29:1109-1123. doi:10.1175/1520-0469(1972)029<1109:DOGS $\mathrm{CC}>2.0 . \mathrm{CO} ; 2$

Majda AJ, Khouider B (2004) A model for convectively coupled tropical waves: nonlinearity, rotation, and comparison with observations. J Atmos Sci 61:2188-2205. doi:10.1175/1520-0469(2004)061<2188:amfcct>2.0.co;2

Mapes B, Tulich S, Lin J, Zuidema P (2006) The mesoscale convection life cycle: building block or prototype for large-scale tropical waves? Dyn Atmos Oceans 42:3-29. doi:10.1016/j. dynatmoce.2006.03.003

Masunaga H, L'Ecuyer TS, Kummerow CD (2006) The MaddenJulian oscillation recorded in early observations from the Tropical Rainfall Measuring Mission (TRMM). J Atmos Sci 63:27772794. doi:10.1175/jas3783.1

Matthews AJ, Baranowski DB, Heywood KJ, Flatau PJ, Schmidtko S (2014) The surface diurnal warm layer in the Indian Ocean during CINDY/DYNAMO. J Climate 27:9101-9122. doi:10.1175/ JCLI-D-14-00222.1

McLay JG, Flatau MK, Reynolds CA, Cummings J, Hogan T, Flatau PJ (2012) Inclusion of sea-surface temperature variation in the US Navy ensemble-transform global ensemble prediction system. J Geophys Res 117:24. doi:10.1029/2011jd016937

Neale R, Slingo J (2003) The maritime continent and its role in the global climate: a GCM study. J Climate 16:834-848. doi:10.1175/1520-0442(2003)016<0834:tmcair>2.0.co;2

Oh J-H, Kim B-M, Kim K-Y, Song H-J, Lim G-H (2013) The impact of the diurnal cycle on the MJO over the Maritime Continent: a modeling study assimilating TRMM rain rate into global analysis. Climate Dyn 40:893-911. doi:10.1007/s00382-012-1419-8

Peatman SC, Matthews AJ, Stevens DP (2014) Propagation of the Madden-Julian Oscillation through the Maritime Continent and scale interaction with the diurnal cycle of precipitation. Q J R Meteorol Soc 140:814-825. doi:10.1002/qj.2161

Praveen Kumar B, Vialard J, Lengaigne M, V. S. N. Murty, McPhaden MJ, Cronin MF, Pinsard F, Gopala Reddy K (2013) TropFlux wind stresses over the tropical oceans: evaluation and comparison with other products. Clim Dyn 40:2049-2071. doi:10.1007/ s00382-012-1455-4

Roundy PE (2008) Analysis of convectively coupled Kelvin waves in the Indian ocean MJO. J Atmos Sci 65:1342-1359. doi:10.1175 /2007jas2345.1

Roundy PE, Frank WM (2004) A climatology of waves in the equatorial region. $J$ Atmos Sci 61:2105-2132. doi:10.1175/1520-0469(2004)061<2105:acowit>2.0.co;2

Ruppert JH (2016) Diurnal timescale feedbacks in the tropical cumulus regime. J Adv Model Earth Syst 8:1483-1500. doi:10.1002/ 2016MS000713
Ruppert JH, Johnson RH (2015) Diurnally modulated cumulus moistening in the preonset stage of the Madden-Julian oscillation during DYNAMO. J Atmos Sci 72:1622-1647. doi:10.1175/ JAS-D-14-0218.1

Ruppert JH, Johnson RH (2016) On the cumulus diurnal cycle over the tropical warm pool. J Adv Model Earth Syst. doi:10.1002/2 $015 \mathrm{MS} 000610$

Schreck CJ III (2015) Kelvin waves and tropical cyclogenesis: a global survey. Mon Weather Rev 143:3996-4011. doi:10.1175/ mwr-d-15-0111.1

Schreck CJ III (2016) Convectively coupled kelvin waves and tropical cyclogenesis in a semi-Lagrangian framework. Mon Weather Rev 144:4131-4139. doi:10.1175/mwr-d-16-0237.1

Silva Dias PL, Schubert WH, DeMaria M (1983) Large-scale response of the tropical atmosphere to transient convection. J Atmos Sci 40:2689-2707. doi:10.1175/1520-0469(1983)040<2689:LSROT $\mathrm{T}>2.0 . \mathrm{CO} ; 2$

Silva Dias PL, Bonatti JP, Kousky VE (1987) Diurnally forced tropical tropospheric circulation over South America. Mon Weather Rev 115:1465-1478. doi:10.1175/1520-0493(1987)115<1465:DFTT $\mathrm{CO}>2.0 . \mathrm{CO} ; 2$

Straub KH, Kiladis GN (2003) Extratropical forcing of convectively coupled Kelvin waves during austral winter. J Atmos Sci 60:526543. doi:10.1175/1520-0469(2003)060<0526:efocck $>2.0$.co;2

Straub KH, Haertel PT, Kiladis GN (2010) An analysis of convectively coupled Kelvin waves in 20 WCRP CMIP3 global coupled climate models. J Climate 23:3031-3056. doi:10.1175/2009j cli3422.1

Wheeler M, Kiladis GN (1999) Convectively coupled equatorial waves: analysis of clouds and temperature in the wavenumber-frequency domain. J Atmos Sci 56:374-399. doi:10.1175/1520-0469(1999)056<0374:ccewao > 2.0.co;2

Yang Q, Majda AJ (2014) A multi-scale model for the intraseasonal impact of the diurnal cycle of tropical convection. Theor Comput Fluid Dyn 28:605-633. doi:10.1007/s00162-014-0336-3

Yang G-Y, Hoskins B, Slingo J (2007) Convectively coupled equatorial waves. Part III: synthesis structures and their forcing and evolution. J Atmos Sci 64:3438-3451. doi:10.1175/JAS4019.1

Yoneyama K, Zhang C, Long CN (2013) Tracking pulses of the Madden-Julian oscillation. Bull Am Meteorol Soc 94:1871-1891. doi:10.1175/BAMS-D-12-00157.1

Yu L, Jin X, Weller RA (2008) Multidecade global flux datasets from the Objectively Analyzed Air-sea Fluxes (OAFlux) project: latent and sensible heat fluxes, ocean evaporation, and related surface meteorological variables. Woods Hole Oceanographic Institution OAFlux Project Technical Report, OA-2008-01, p 64

Zhang C (2005) Madden-Julian oscillation. Rev Geophys 43:RG2003. doi:10.1029/2004RG000158

Zhang C, Webster PJ (1992) Laterally forced equatorial perturbations in a linear model. Part I: stationary transient forcing. J Atmos Sci 49:585-607. doi:10.1175/1520-0469(1992)049<0585:LFEPIA> 2.0.CO;2

Zhang C, Gottschalck J, Maloney ED, Moncrieff MW, Vitart F, Waliser DE, Wang B, Wheeler MC (2013) Cracking the MJO nut. Geophys Res Lett 40:1223-1230. doi:10.1002/grl.50244 